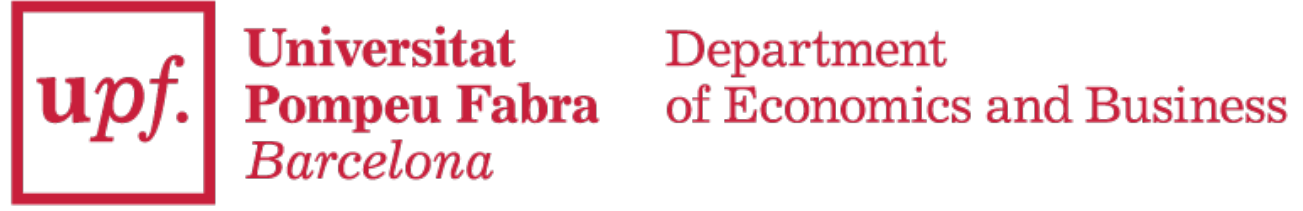

Economics Working Paper Series

Working Paper No. 1605

\title{
Beliefs and consumer search in a vertical industry
}

Maarten Janssen and Sandro Shelegia

March 2018 


\title{
Beliefs and Consumer Search in a Vertical Industry*
}

\author{
Maarten Janssen ${ }^{\dagger}$ and Sandro Shelegia ${ }^{\ddagger}$
}

March 20, 2018

\begin{abstract}
This paper studies vertical relations in a search market. As the wholesale arrangement between a manufacturer and its retailers is typically unobserved by consumers, their beliefs about who is to be blamed for a price deviation play a crucial role in determining wholesale and retail prices. The common assumption in the consumer search literature is that consumers exclusively blame an individual retailer for a price deviation. We show that in the vertical relations context, predictions based on this assumption are not robust in the sense that if consumers assign just a small probability to the event that the upstream manufacturer is responsible for the deviation, equilibrium predictions are qualitatively different. For the robust beliefs, the vertical model can explain a variety of observations, such as retail price rigidity (or, alternatively, low cost pass-through), non-monotonicity of retail prices in search costs, and (seemingly) collusive retail behavior. The model can be used to study a monopoly online platform that sells access to final consumers.
\end{abstract}

JEL Classification: D40; D83; L13

Keywords: Vertical Relations, Consumer Search, Double Marginalization, Product Differentiation, Price Rigidities

*We have benefitted from comments by Natalia Fabra, Doh-Shin Jeon, Dmitry Lubensky, Jose-Luis Moraga-Gonzalez, Alexei Parakhonyak, Patrick Rey, Andrew Rhodes, Anton Sobolev, Chris Wilson and participants to the IV workshop on Consumer Search (Moscow) and seminars in Barcelona, Milan and Paris, Toulouse, XXIX Jornadas de Economia Industrial 2014 and EARIE 2017. Shelegia acknowledges financial support from the Spanish Ministry of Science and Innovation grant MINECO ECO2014-59225P. Shelegia acknowledges financial support from the Spanish Ministry of Economy and Competitiveness, through the Severo Ochoa Programme for Centres of Excellence in RD (SEV-2015-0563).

${ }^{\dagger}$ Department of Economics, University of Vienna and State University Higher School of Economics. Email: maarten.janssen@univie.ac.at

${ }_{\ddagger}^{\ddagger}$ Department of Economics and Business, Universitat Pompeu Fabra and Barcelona GSE. Email: sandro.shelegia@upf.edu. 


\section{Introduction}

In consumer search markets, the market power of firms depends on consumers' willingness to search. When at a firm, consumers compare the benefit of buying now with the expected benefit of continuing to search. The expected benefit of search crucially depends on the price consumers believe the next firm charges. As beliefs determine how consumers react to price changes, they are important in determining how profitable price changes are. If consumers are pessimistic about whether the next search will yield a good offer (low price), they are more likely to accept the current offer, giving firms incentives to set higher prices.

This basic insight is important in any search market, but - as we will argue in this paper - it is particularly important in vertically related markets where a supplier (or manufacturer) sells an input to firms (or retailers) who sell to final consumers searching for good product matches and prices. One may think of a variety of product markets, such as the ones for electronic products, where retailers' marginal cost to a large extent is determined by the wholesale price that is chosen by the manufacturer. In these environments, the final retail price a consumer observes is the product of the input price set by the manufacturer and the way the retailer reacts to that price. As consumers typically do not know the wholesale arrangement between retailers and manufacturers, consumers may 'blame' either the retailer or the manufacturer or both for any deviation from the price they anticipated to observe. Consumers' beliefs about retail prices that are not yet observed may then depend on the retail prices consumers observe at the firm they are visiting currently as consumers may reason that these prices move together in response to the wholesale price that is set by the common manufacturer.

To focus on this key idea, we model the interaction between one monopoly input supplier who offers a (possibly) non-linear contract to two independent retailers who compete in a search market a la Wolinsky (1986). We then make two key contributions.

First, we make a methodological contribution by demonstrating that the behavior of firms in vertically related markets critically depends on whom consumers blame for deviations from equilibrium prices. In the literature following Wolinsky (1986), ${ }^{1}$ the typical assumption is that if consumers observe an unexpected (i.e., non-equilibrium) price, they believe that firms that are not yet visited sell at the equilibrium price. We show that using this assumption in a vertical industry leads to predictions that are not robust, in the sense that, if consumers believe that there is even an arbitrarily small chance that the common supplier is responsible for an unexpected retail price they observe, then the equilibrium is qualitatively different. In particular, we show that if consumers fully

\footnotetext{
${ }^{1}$ Starting from Anderson and Renault (1999), there is a wide range of recent papers that build on the Wolinsky model. See, e.g., Anderson and Renault (2006), Bar-Isaac, Caruana and Cunat (2011), Armstrong, Vickers and Zhou (2009), Zhou (2014), and Armstrong and Zhou (2015), among others. All these papers employ what we will call in this paper the standard or typical assumption.
} 
blame individual retailer for deviations from the equilibrium price, then a pure strategy equilibrium does not exist if the search costs are intermediate, whereas for larger search costs the market will partially break down in the sense that consumers who are unsatisfied with their product match at the first firm drop out of the market rather than search further. If consumers (at least partially) blame the monopoly supplier for observed nonequilibrium prices, then a pure strategy equilibrium always exists and the supplier is largely able to prevent the market breakdown.

Our second contribution is more substantial. We show that combining the vertical relations literature with the search literature a la Wolinsky (1986) yields new explanations for such diverse phenomena as price rigidities and other forms of low cost pass-through rates, a non-cooperative explanation for seemingly collusive behavior at the retail level, and non-monotonicity of retail prices in search costs.

To fully explain these results, it is convenient to first explain an intermediate result regarding downstream market. In particular, there is a discontinuous drop in retail sales (partial market break down) if search cost surpasses a threshold value. To understand how this happens, it is important to relate the Wolinsky model to the Diamond Paradox (Diamond, 1971). Diamond showed that with homogenous goods, for any positive search cost, there will be no search beyond the first firm and all firms will charge the monopoly price. As pointed out By Anderson and Renault (1999), Wolinsky solved the paradox by introducing product differentiation, giving some consumers incentives to search. However, when the search cost is sufficiently high and so prices are high, Wolinsky's solution fails because even consumers with very low utility draws are not willing to pay the search cost to try their luck at a second firm if they expect prices to be high. As a result, when the search cost exceeds a threshold, firms' demand consists of first visits only which leads to a demand drop because consumers discover fewer favorable matches. The existence of such a search cost threshold, and the associated partial market breakdown has not been explored in the search literature before. Without the interaction with an upstream firm, this partial market breakdown is independent of the assumption concerning consumer beliefs, but it plays an important role in explaining the non-robustness of the equilibrium predictions under the assumption that consumers exclusively blame the individual retailer they visit for deviations from the expected (equilibrium) price.

Using this intermediate result, we now explain that if consumers at least partially blame the monopoly supplier for deviations from an anticipated retail price, the retail price is non-monotonic in search cost. For relatively small search costs, the price is increasing in search cost (as in the standard model). At intermediate values of the search cost, firms charge prices that are equal to the reservation utility. Since the latter is decreasing in the search cost, so are prices. ${ }^{2}$ Overall, in this range the price is hump-shaped in

\footnotetext{
${ }^{2}$ This inverse relationship between search cost and prices is unlike the earlier contributions with the same conclusion. In Janssen, Moraga-González and Wildenbeest (2005), the search cost changes the
} 
search cost. Interestingly, at the maximum, both firms set the price that a monopolist selling both goods would set. This price is higher than the single-good monopoly price because a joint profit maximization internalizes demand externalities between the two (substitute) goods. Thus, for intermediate search costs when consumers blame a common supplier for unexpected retail prices a fully collusive outcome results even though firms act non-cooperatively!

Another way in which this intermediate result is used is in demonstrating that retail prices may be sticky relative to changes in the supplier's wholesale price (or other components of retailers' marginal cost). Fixing the search cost, we may investigate how the downstream equilibrium changes as the downstream marginal cost increases. This perspective is important in vertically related markets where the input price set by the supplier plays the key role. Under the typical assumption where consumers exclusively blame individual retailers for unexpected prices, the final consumer price is always increasing in a firm's marginal cost. When consumers hold the supplier at least partially responsible for unexpected prices, there is an intermediate level of the retailers' marginal cost where the retail price equals the reservation utility, and because the reservation utility does not depend on the marginal cost, neither does the retail price. So, under these robust consumer beliefs, the retail price is first increasing in retailers' cost, then constant, and then increasing again.

Equipped with these results in the downstream market, we can investigate the vertically related market where retailers' cost is partially determined by an upstream supplier. Under the typical assumption where consumers exclusively blame the individual retailer they visited for setting an unexpected price, the equilibrium structure is as follows. For low search costs, the manufacturer sets a wholesale price such that retail prices are smaller than the reservation utility and consumers search beyond the first firm if the utility draw at the first firm they visited was low. For high search costs, the supplier's optimal price is such that retail prices will be higher than the reservation utility, consumers do not search beyond the first firm and (despite the possibility of offering non-linear wholesale contracts) a classic double-marginalization outcome results. For intermediate search cost, a pure strategy equilibrium does not exist.

For any other belief, where consumers assign a positive probability to the event that the common supplier is responsible for an unexpected price change, market outcomes are very different. The behavioral patterns we have already discussed (price rigidities, seemingly collusive behavior, non-monotonicity in search cost) remain, and get even further strengthened when we include the optimal pricing behavior of the supplier. As the supplier's indirect demand consists of the demand of both retailers, the supplier has an

composition of heterogeneous consumers and may result in lower prices at higher search cost. In Zhou (2014) consumers search for multiple products. In this environment, products are search complements and if the search cost increases, firms may compete more intensely to prevent consumers searching further. 
incentive to induce the retailers to charge the joint profit maximizing prices. As he affects the retail prices through the choice of the per unit wholesale price, he is also in partial control of the beliefs consumers have. Given this incentive and the ability to implement it, he sets an input price that maximizes the profits of the vertical structure (and extracts all the profits with the fixed fee). For larger search cost, to avoid market breakdown, he will make sure that the retail prices are not larger than the reservation utility. Retailers would not by themselves do so because they are not interested in encouraging their own consumers to search further. The upstream supplier does care because more search means results in higher total demand. The fact that beliefs move with prices conveniently prevents the upstream firm from deviating to inducing higher retail prices because consumers update their beliefs and stop searching. To the best of our knowledge, there is no other paper where a firm proactively seeks to prevent the Diamond Paradox from arising.

There is a small, but growing literature that combines consumer search with vertical relations. Janssen and Shelegia (2015) demonstrates that the fact that wholesale price arrangements are unknown to consumers has an important qualitative and large quantitative impact on market outcomes. They use the Stahl (1989) search model for homogeneous goods to make this point. Garcia, Janssen and Honda (2017) extend the analysis to multiple manufacturers and show that the vertical search model can explain the frequently observed phenomenon of bimodal retail prices. Lubensky (2017) introduces vertical relations in the model of Wolinsky (1986) to study the role of recommended retail prices, while Asker and Bar-Isaac (2017) focus on the impact of another vertical restraint, namely minimum advertised prices (MAPs).

The paper is also related to the nascent literature on competition on platforms, like amazon.com or booking.com (see, e.g., Wang and Wright (2017)). That literature studies the interaction between the fees platform(s) set to allow firms sell through their website and the pricing policies of the firms themselves in a world where consumers search for products on the platform(s), but may also buy from the firms directly. An important policy debate in this regard is on whether most favored nation clauses lead to higher prices or not. In terms of this literature, our paper can be re-interpreted in the following way. The input provider is the platform and the essential input he provides is the access to consumers. In our paper, the firms cannot sell to consumers outside of the platform. This captures the fact that for certain products in the online world many sellers are not Known to consumers and therefore firms will not be able to sell to them without being listed on the platform. ${ }^{3}$ As we have a monopoly supplier, we do not model platform competition, unlike e.g., Karle, Peitz and Reisinger (2017), but what we bring to the literature is the

\footnotetext{
${ }^{3}$ ? review evidence by the UK's Competition and Market Authority (CMA) showing that price comparison websites have heavily invested in establishing a brand name and that depending on the product, many consumers are loyal to a platform and search only there. See, e.g., https://assets.publishing.service.gov.uk/media/58e224f5e5274a06b3000099/

dcts-consumer-research-final-report.pdf.
} 
focus on consumers not knowing the pricing arrangement between firms and the platform and how their ignorance affects search behavior and, as a consequence, the pricing policies of firms and platform. The above literate has not focused on this issue. ${ }^{4}$

The rest of the paper is organized as follows. In Section 2 we set up the model, discuss the equilibrium concept used and explain the search and demand behavior of consumers and how this depends on the information consumers possess and the beliefs they hold. In Section 3 we analyze the downstream market and show how firms' pricing depends on whom consumers hold responsible for unexpected price observations. In Section 4, we provide the full equilibrium analysis by analyzing the optimal behavior of the supplier and show what type of equilibrium predictions result for different beliefs. Section 5 concludes. Proofs are contained in the Appendix.

\section{The Model and Equilibrium Concept}

The retail side of the model we study follows Wolinsky (1986). There are two firms, 1 and 2, who have a common cost $c$ per unit. The firms transform the input into a final differentiated good, using a one-for-one technology. There is a unit mass of consumers per firm. Utility to a consumer from buying the good at firm $i$ is $v_{i}$. This utility is drawn from the distribution function $G(v)$, with the corresponding density $g(v)$, which is the same for both firms and defined over the (possibly infinite) interval $[\underline{v}, \bar{v}]$. As is standard in the literature (see e.g., Anderson and Renault (1999)), we require that $1-G(v)$ is log-concave. A consumer's valuation for firm 1's product is independent of his valuation for firm 2's product. A consumer visits one of the firms at random and finds out $v_{i}$ and $p_{i}$. After observing the match value $v_{i}$ and the price $p_{i}$ the consumer decides whether or not to visit the second firm. If she does so, she makes her purchase to get the best available surplus $v_{i}-p_{i}$, provided that it exceeds zero, the outside option. We assume that the first visit is free. ${ }^{5}$ The second visit is costly, and the cost is denoted by $s$. If after visiting the first firm, a consumer decides to search the second firm, she can always go back to the first firm at no additional cost (free recall). The above set-up is common to all consumer search models based on Wolinsky (1986).

We now turn to the monopolist supplier. The supplier offers both downstream firms a common two-part tariff consisting of a unit wholesale price $w$ and a fixed fee $F$. Firms have to spend $t$ to transform the homogenous input into the differentiated output they sell, so that each firm's marginal cost is given by $c=w+t$. We can interpret the two levels of the supply chain in different ways: two firms with a common supplier, or two retailers selling a product of the same manufacturer, or two firms buying access to final

\footnotetext{
${ }^{4}$ Wang and Wright (2017) assume that the fee charged by the platform is known to consumers.

${ }^{5}$ Most of our results continue to hold if the first search is costly. There is a slight difference in results when $s$ (or $t$-see below) is large and in Section 4 we comment on how the results would change if the first search is also costly.
} 
consumers via a monopoly platform. Accordingly, we can interpret $t$ as the marginal cost of transformation, or a retailer's shelving cost or a unit sales tax, or the firms' own cost of production (on top of the access fee to consumers) or a combination of these. We use these interpretations interchangeably.

As consumers do not know firms' prices (before observing them), it is natural to also assume that consumers do not observe the wholesale contract. ${ }^{6}$ Note that the final price consumers observe is the end result of the wholesale price set by the supplier and the firm's pricing strategy (a price for any given input price). After observing an out-ofequilibrium retail price, consumers may hold any belief regarding who has deviated from the equilibrium path. They may put full responsibility on either the downstream firm or the upstream firm, or they may hold both parties partly responsible. If they believe that the firm they visited has deviated, then they aught to think that the other downstream firm's price is unchanged. At the other extreme, if they believe that the supplier has charged a different wholesale price affecting all firms, then they may expect the other downstream firms to react in the same way to the upstream firm's deviation. ${ }^{7}$

To study the role of consumer beliefs in sustaining market outcomes, we introduce the following notation. Denote by $p^{*}$ the equilibrium price a consumer expects to encounter at both stores in the symmetric equilibrium. If a consumer, on his first search, encounters an out-of-equilibrium price $p_{i} \neq p^{*}$, he has to form a (point) belief $p_{j}^{e}$ of the price set by firm $j$ that has not been yet visited. If the consumer only 'blames' the firm he has visited first for the deviation, then he believes that the firm not yet visited has set $p_{j}^{e}=p^{*}$. On the other hand, if the consumer blames the upstream firm, then he believes that the firm not yet visited sets $p_{j}^{e}=p_{i}$. In general, if the consumer holds both parties partly responsible, their beliefs may be a convex combination of the previous two cases, i.e., $p_{j}^{e}=\alpha p^{*}+(1-\alpha) p_{i}$ for a given $\alpha \in[0,1]$. Any other relationship between $p_{j}^{e}$ and $p_{i}$ and $p^{*}$ may hold, provided that for $p_{i}=p^{*}$ we have $p_{j}^{e}=p^{*}$, but in this paper, for expositional simplicity, we focus on the linear form provided here. ${ }^{8}$

The equilibrium notion we employ is formally defined as follows.

Definition 1. For a given $t$, a symmetric perfect Bayesian equilibrium is a wholesale

\footnotetext{
${ }^{6}$ In the context of the Stahl (1989) sequential search model for homogeneous goods, Janssen and Shelegia (2015) focus on the comparison of markets where consumers observe the wholesale price and markets where they do not observe the wholesale price. We focus here on the role of consumer beliefs where consumers do not observe the wholesale price. In the earlier version of this paper we also considered the vertical relations model where the wholesale price is observed by consumers, and confirmed Janssen and Shelegia's finding that, holding beliefs the same, prices are higher when the wholesale price is unobserved.

${ }^{7}$ Without vertical relations, the consumer search literature implicitly or explicitly uses "passive" beliefs. In terms of the notation to be introduced shortly, passive beliefs imply $p_{j}^{e}$ is independent of $p_{i}$ (corresponding to $\alpha=1$ ). The vertical contracting literature (see, e.g., Hart et al. (1990) and McAfee and Schwartz (1994)) also considers "symmetric" beliefs, which in our setting can be described as $p_{j}^{e}=p_{i}$ : consumers who first visit firm $i$ believe that firm $j$ charges the same price as $i$.

${ }^{8}$ As will become apparent later, most of our results depend on the derivative of $p_{j}^{e}$ with respect to $p_{i}$ around $p_{i}=p^{*}$, which in the linear formulation is simply equal to $1-\alpha$.
} 
contract $\left(w^{*}, F^{*}\right)$, a contract acceptance strategy and a retail pricing strategy $p^{*}(c)$ for the firms, and a reservation utility $r(p)$ such that

1. The supplier chooses $(w, F)$ so as to maximize its profit given the contract acceptance strategy and the pricing strategy $p^{*}(c)$ of the firms, and consumers' reservation utility $r(p)$;

2. Each firm $i$ decides to accept or reject $(w, F)$. If the firm accepts, it chooses $p_{i}(c)=$ $p^{*}(c)$ to maximize its expected profit given the pricing strategy $p^{*}(c)$ of the other firm and consumers' reservation utility $r(p)$;

3. Consumers follow an optimal reservation search rule given their beliefs, the match value $v_{i}$ and the price $p_{i}$ they observe at firm $i$;

4. Consumers' common belief about the price set by the firm that is not yet visited, $p_{j}^{e}$, given the price they have observed, $p_{i}$, satisfies $p_{j}^{e}=\alpha p^{*}\left(c^{*}\right)+(1-\alpha) p_{i}$ for some $\alpha \in[0,1]$.

It is important to understand why we focus on the duopoly case. First, focusing on duopoly allows us to avoid the issue of belief formation after two different prices have been observed. As there is no obvious way to do this, the focus on duopoly simplifies the analysis considerably. In particular, with two firms, a consumer can update her belief only once (after visiting the first firm) making belief formation relatively straightforward. For three or more firms, it may be the case that, after having searched two firms, a consumer has observed two different prices and needs to update his belief in order to decide whether to continue to search or not. Second, regardless of how subsequent beliefs are formed, the issues we uncover in the duopoly model are still relevant because they concern the first search. In fact, by virtue of the fact that consumers are more, and often much more, likely to search once rather than to search two or more times, our analysis is of first-order relevance even in oligopoly models.

\subsection{Consumer Behavior}

Given that the wholesale contract is unobserved by consumers (who move last), there are no subgames of the model that can be analyzed on their own. However, before analyzing the supplier's behavior, it is still useful to first analyze the behavior of consumers and downstream firms for a given input price $w$. In this subsection, we specify how the downstream firms' demand depends on consumer beliefs.

Consider a consumer who visits firm $i$. A reservation utility strategy is a strategy where the consumer continues to search if the utility drawn is below a certain threshold, and stops if the utility exceeds this threshold. This threshold depends on the utility realization, firm $i$ 's price and the belief about firm $j$ 's price. Before finding it, we determine the reservation 
utility $r$, a utility level at which a consumer is indifferent between searching the second firm, or accepting $r$, assuming that both firms charge equal prices. The reservation utility $r$ is the solution to

$$
\int_{r}^{\bar{v}}(v-r) g(v) d v=s
$$

if the solution exists, and is equal to $r=\underline{v}$ if it does not.

The threshold utility level is then simply computed as $r$ plus the (expected) price difference. Formally, a consumer who draws $v_{i}$ and $p_{i}$ prefers to search rather than to accept the current offer if

$$
v_{i}<r+\left(p_{i}-p_{j}^{e}\right)
$$

The consumer has, however, a third option, namely not to continue to search and not to buy. For the consumer to continue to search we need an additional condition to hold, namely that her reservation utility exceeds the price expected at the other firm, $r \geq p_{j}^{e}$; otherwise the expected benefit from search is negative and the consumer does not search beyond the first firm.

Given the optimal search behavior above, we can write down firm i's demand. As the expression below shows this demand differs from the standard expression in the literature following Wolinsky (1986) in several respects. The expression allows firm $i$, whose demand is being computed, to set a price $p_{i}$, which may differ from all of the following: $(i)$ the price $p_{j}$ of its rival, $(i i)$ the belief $p_{i}^{e}$ consumers who make their first visit to firm $j$ hold about the price of firm $i$, and $(i i i)$ the belief $p_{j}^{e}$ consumers who make their first visit to firm $i$ first hold about firm $j$ 's price. When deriving the equilibrium price, the search literature based on the Wolinsky model sets all $p_{j}, p_{j}^{e}$ and $p_{i}^{e}$ equal to the candidate equilibrium price $p^{*}$. We need to isolate all four because in the vertical relations model upon a deviation by the supplier from $w^{*}$, if firm $i$ is itself deciding whether to deviate or not, it may find itself in a situation where all four terms are different from each other.

Firm $i$ 's demand is given by

$$
\begin{aligned}
& q_{i}\left(p_{i}, p_{j}, p^{*}\right)=\left(1-G\left(p_{i}+\max \left\{r-p_{j}^{e}, 0\right\}\right)\right)+\int_{p_{i}}^{p_{i}+\max \left\{r-p_{j}^{e}, 0\right\}} G\left(p_{j}-p_{i}+v\right) g(v) d v \\
& +\left[G\left(r-p_{i}^{e}+p_{j}\right)\left(1-G\left(r-p_{i}^{e}+p_{i}\right)\right)+\int_{p_{i}}^{r-p_{i}^{e}+p_{i}} G\left(p_{j}-p_{i}+v\right) g(v) d v\right] \cdot I_{r \geq p_{i}^{e} .}
\end{aligned}
$$

The first term is the demand from consumers who visit firm $i$ and buy outright because their utility draw is higher than the threshold $r-p_{j}^{e}+p_{i}$. The second term is the demand from those consumers who first visit firm $i$, draw a utility below $r-p_{j}^{e}+p_{i}$, visit firm $j$, but come back and buy from firm $i$. The first two groups of consumers only search when $r \geq p_{j}^{e}$, and otherwise the firm's demand from them is simply $1-G\left(p_{i}\right){ }^{9}$ The first term in square brackets is the demand from consumers who first visit firm $j$, draw a value $v_{j}$

\footnotetext{
${ }^{9}$ This is the reason why we write $\max \left\{r-p_{j}^{e}, 0\right\}$.
} 
that is lower than the threshold value $r-p_{i}^{e}+p_{j}$, decide to visit firm $i$, find a utility draw $v_{i}$ that is higher than $r-p_{i}^{e}+p_{i}$ and buy from firm $i$. The second term inside the square brackets is similar to the first one, but accounts for those consumers who first visit firm $j$, decide to search firm $i$, also draw a relatively low value at firm $i$, but still buy at firm $i$ as that price/product offer is better than that offered by firm $j$. These two terms are multiplied by an indicator function $I_{r \geq p_{i}^{e}}$ that is equal to 1 when $r \geq p_{i}^{e}$. In the opposite case consumers arriving first to firm $j$ never continue to search, and thus they never purchase from firm $i$.

The demand expression for firm $i$ is illustrated in Figure 2 in $\left(v_{I}, v_{j}\right)$ space for the case where $r \geq p_{k}^{e}, k=i, j$. Area A corresponds to the first term in (2) which refers to consumers who arrive at firm $i$ first, draw $v_{i}$ above $r-p_{i}+p_{j}^{e}$ and buy outright. Area $\mathrm{B}$ corresponds to consumers who arrive at firm $i$ first but continue to search because their utility draw $v_{i}$ is smaller than $r-p_{i}+p_{j}^{e}$ and then come back to buy because their utility draw at firm $j$ is even worse (the second term in (2)). Areas C and D correspond to consumers who first visit firm $j$, draw a utility level $v_{j}$ that is smaller than $r-p_{j}+p_{i}^{e}$, continue to search firm $i$ and purchase there as their utility at firm $i$ is higher than $p_{i}$ and higher than the utility at firm $j$. Note that consumer beliefs affect who searches, but not whether consumers buy or not.

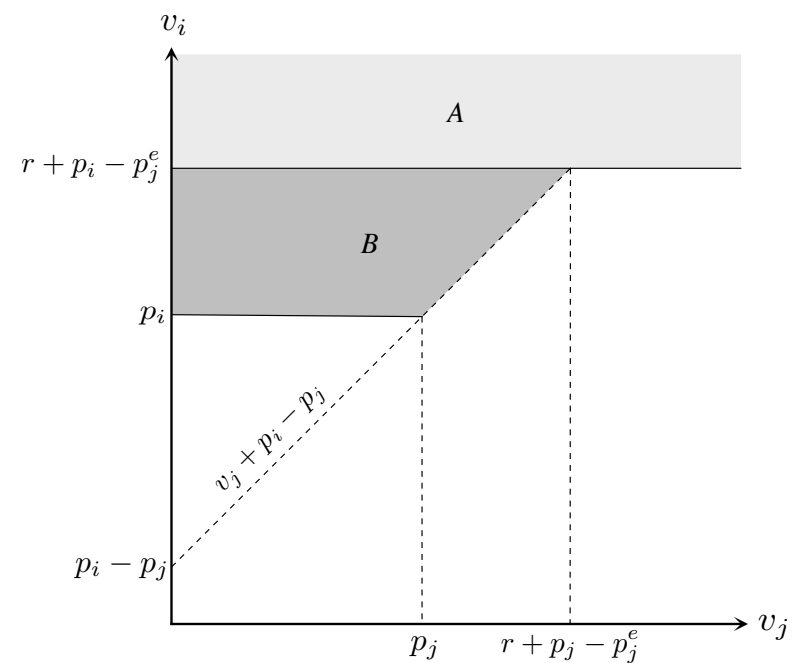

i)

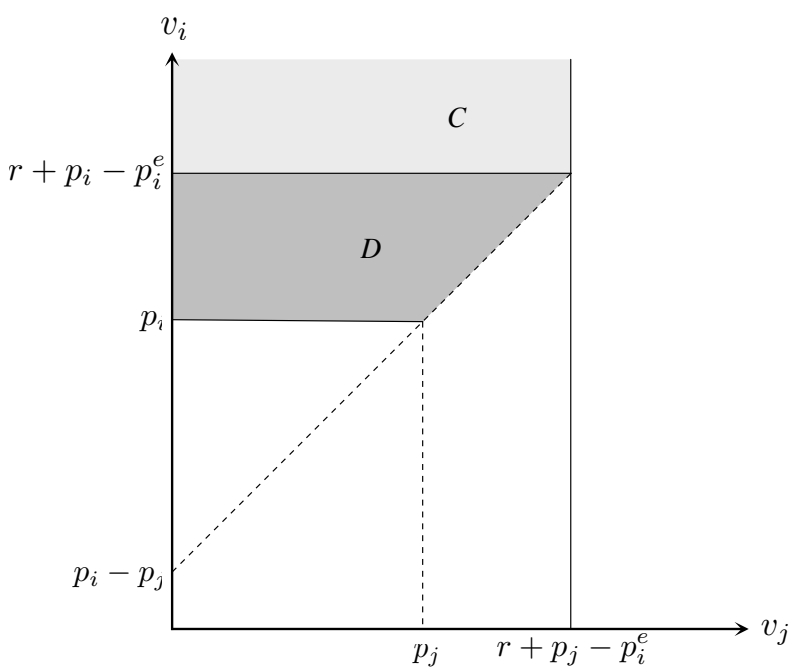

$i i)$

Figure 1: Figures i) and ii) depict consumers who buy from firm $i$ after having made a first visit to firm $i$ and firm $j$, respectively.

\section{Downstream Behavior}

In this section we study how the downstream pricing behavior depends on the wholesale price $w$. This is important for several reasons. First, as we will show, the downstream behavior is interesting in its own right. Namely, low cost pass through and seemingly 
collusive behavior emerge as the result of this isolated analysis of the downstream level. Second, to determine the overall equilibrium for the vertical model, when choosing the wholesale arrangement $\left(w^{*}, F^{*}\right)$ optimally, the supplier needs to consider how retailers would react to deviations from the equilibrium wholesale arrangement.

Thus, consider the downstream market for a given input price $w$ and consumers that have a prior belief (before searching any firm) that the symmetric equilibrium downstream price is $p^{*}$. (This belief corresponds to the equilibrium wholesale price $w^{*}$ ). Each firm observes $(w, F)$ and has to decide whether to accept this wholesale contract, and if so, what price to set. If they accept, they will set a price $p(w)$ to sell to consumers. At this stage we allow both that $p(w) \neq p_{i} \neq p^{*}$ and that $w \neq w^{*}$, so that once we want to study the supplier's optimal pricing strategy we can calculate the supplier's deviation payoff for any $w \neq w^{*}$. As the outside option of a downstream firm is not to sell anything, it will accept any contract if the expected profit of setting $p(w)$ is larger than or equal to 0 , provided that the other players acts according to the equilibrium.

For a given expected (equilibrium) downstream price $p^{*}$ by consumers and a wholesale contract $(w, F)$ we define a downstream market equilibrium as follows. Note that as consumers do not observe the same wholesale contract $(w, F)$, the downstream behavior cannot be analyzed as a separate subgame of the whole game. Still, and this will be important in the next section, as both downstream firms observe $(w, F)$ there is some strategic interaction between them. To clarify that consumers do not observe the wholesale contract, this strategic interaction is conditional on consumer beliefs, represented by $p^{*}$.

Definition 2. Fix $\alpha$ and s. For a given expected downstream price $p^{*}$ and a wholesale contract $(w, F)$, a symmetric downstream market equilibrium is a function $p(w)$ and an acceptance decision such that (i) $p(w)$ is the optimal pricing decision given that the other firm chooses the same price, the wholesale contract is given by $(w, F)$ and demand is given by (2) and (ii) each firm makes nonnegative profits given both firms choose $p(w)$.

In this section, we will derive the symmetric equilibrium price $p(w)$ which may be different from $p^{*}$ if $w \neq w^{*}$. To this end, consider firm $i$ who is contemplating to charge $p_{i}$ when the other firm is expected to charge the equilibrium price $p(w)$. In order to facilitate this derivation, we will first define for $\alpha<1$

$$
\bar{p} \equiv \frac{r-\alpha p^{*}}{1-\alpha}
$$

as the threshold price such that when $p_{i}=\bar{p}$ we have $p_{j}^{e}\left(p_{i}\right)=r$. Since $\frac{\partial p_{j}^{e}\left(p_{i}\right)}{\partial p_{i}}=1-\alpha$, for $\alpha<1$ if $p_{i}$ exceeds $\bar{p}$ consumers who first visit firm $i$ will not search further if their match value with firm $i$ is too low. For future reference, note that $\bar{p}$ is (weakly) decreasing in $s$. This is because the higher the search cost, the lower the reservation utility, and therefore the lower is the threshold price $r$ at which consumers stop searching. The 
case where $\alpha=1$ is special and in the next section we show that taking the upstream manufacturer into account, the equilibrium predictions of the vertical model for $\alpha=1$ are not robust and they differ in important qualitative ways from the model where $\alpha<1$. For now, to characterize the downstream equilibrium laying the groundwork for the next section, we will define $\bar{p}$ to be $-\infty$ when $p^{*}>r$ and $+\infty$ for $p^{*} \leq r$ for the case where $\alpha=1$.

For a general utility distribution, it is difficult to prove a downstream equilibrium exists. The difficulty is that for general beliefs $p^{*}$ and for $0<\alpha<1$ one has to evaluate the profit function at different values of $G($.$) . The next Proposition shows that equilibrium$ existence is not an issue if $G($.$) is uniform.$

Proposition 1. If the utility distribution $G(v)$ is uniformly distributed on $[0,1]$, then a symmetric downstream equilibrium exists and is unique.

The proof shows that the profit function $\pi_{i}\left(p_{i}, p_{j}, p^{*}\right)=q_{i}\left(p_{i}, p_{j}, p^{*}\right)\left(p_{i}-c\right)$ is concave for $p_{i}<\bar{p}$ and at least quasi-concave for $p_{i}>\bar{p}$. It is also overall concave because the left derivative of the profit function at $p_{i}=\bar{p}$ strictly exceeds the right derivative at the same point implying there is a kink in the profit function at $\bar{p}$. The proof shows that this latter property holds true independently of the uniformity assumption. Thus, the uniform distribution is only used to show the (quasi-)concavity on both sides of the kink. In the rest of the paper we assume that $G($.$) is such that a symmetric equilibrium exists$ and is unique. From the above proposition we know that this is the case for the uniform distribution.

In general, there are three possibilities for the symmetric equilibrium price $p(w)$ : $(i)$ $p(w)<\bar{p}$ and the relevant demand equation is as in (2); (ii) $p(w)=\bar{p}$ whereby profit for both firms is maximized at the kink and $(i i i) p(w)>\bar{p}$ and each firm is a local monopolist with demand $1-G\left(p_{i}\right)$.

Let us start characterizing the first case. If demand is as in (2), then for any $w$ the equilibrium price in the downstream market is characterized by the following condition (where we omit the dependence of $p$ on $w$ ):

$$
p-c=\frac{q_{i}\left(p, p, p^{*}\right)}{-\frac{\partial q_{i}}{\partial p_{i}}\left(p, p, p^{*}\right)}
$$

This is a standard pricing condition for a firm with demand $q_{i}$ and marginal cost $c$. What is worth commenting on is that both the demand, and its derivative with respect to $i$ 's own price are evaluated at $p_{i}=p_{j}=p$, and the initial belief of consumers is allowed to be different from both. After some simple algebra, the above condition transforms into

$$
p-c=\frac{1-G(p)^{2}}{2 \int_{p}^{\alpha \Delta p+r} g(v)^{2} d v+2 g(p) G(p)+\alpha(1-G(\alpha \Delta p+r)) g(\alpha \Delta p+r)},
$$


where $\Delta p=p-p^{*}$. In the overall equilibrium of the vertical industry, the price difference $\Delta p$ is zero. For future reference, the solution to (3) will be denoted by $\tilde{p}$.

In the standard model where $\alpha=1$ and $\Delta p=0$, this pricing rule induces the same price as in Wolinsky (1986), but in general, it is different in two respects. First, the candidate equilibrium price is smaller than in the standard model for any $\alpha<1$. Second, the equilibrium price is decreasing in $\Delta p$, and therefore is increasing in $p^{*}$. Thus, the lower is the price that consumers expect before embarking on search, the lower is the equilibrium price. This is intuitive in that if consumers are more optimistic about finding lower prices in the market, they are more willing to search and thus firms are forced to charge lower prices.

It is trivially true that the solution to (3) is increasing in $c$, so for $p<\bar{p}$ to hold, we need that $c$ is sufficiently low. The threshold, denoted by $c_{1}\left(p^{*}\right)$, is found by substituting $p=\bar{p}$ into (3) and solving for $c$, which gives

$$
c_{1}\left(p^{*}\right) \equiv \bar{p}-\frac{1-G(\bar{p})^{2}}{(\alpha+(2-\alpha) G(\bar{p})) g(\bar{p})} .
$$

If $c<c_{1}\left(p^{*}\right)$, then provided that firm $j$ charges $p_{j}=p(w)$, firm $i$ will maximize the section of its profits to the left of $\bar{p}$ by also charging $p_{i}=p(w)$. In fact, it cannot do better with any $p_{i}>\bar{p}$.

Now consider case (iii) where $p(w)>\bar{p}$, i.e., if the match value at the first firm is low, consumers do not search beyond the first firm. Each firm is then effectively a monopolist facing demand $1-G(p)$, and so the equilibrium price $p(w)=p_{c}^{M}$ where $p_{c}^{M}$ is the standard monopoly price for marginal cost $c$ that solves

$$
p_{c}^{M}=c+\frac{1-G\left(p_{c}^{M}\right)}{g\left(p_{c}^{M}\right)} .
$$

The situation is now reversed. If firm $j$ charges $p_{j}=p_{c}^{M}$, firm $i$ will maximize the section of its profits to the right of $\bar{p}$ by also charging $p_{i}=p_{c}^{M}$. This situation occurs when $p(w)=p_{c}^{M}>\bar{p}$ which holds when $c$ exceeds $c_{2}\left(p^{*}\right)$ found by substituting $\bar{p}$ in (4) for $p_{c}^{M}$ and solving for $c$. This yields

$$
c_{2}\left(p^{*}\right) \equiv \bar{p}-\frac{1-G(\bar{p})}{g(\bar{p})} .
$$

We can now proceed to case (ii) by noting that $c_{2}\left(p^{*}\right)>c_{1}\left(p^{*}\right)$ for $\alpha<1$. $^{10}$ When $c \in\left(c_{1}\left(p^{*}\right), c_{2}\left(p^{*}\right)\right)$, if firm $j$ charges $p_{j}=\bar{p}$, firm $i$ also maximizes its profits with $p_{i}=\bar{p}$. As explained, this is because now the kink at $\bar{p}$ is the maximizer of the overall profits.

Given the above discussion, we characterize the symmetric downstream equilibrium price $p$ as follows.

\footnotetext{
${ }^{10}$ Note that $c_{1}\left(p^{*}\right) \rightarrow c_{2}\left(p^{*}\right)$ if $\alpha \rightarrow 1$, so the region between the two threshold values disappears.
} 
Proposition 2. For given parameter values $s$ and $\alpha$ and a given consumer belief about the downstream price $p^{*}$ the symmetric downstream equilibrium price $p(w)$ is given by

$$
p(w)= \begin{cases}\tilde{p} & \text { if } c \leq c_{1}\left(p^{*}\right) \\ \bar{p} & \text { if } c_{1}\left(p^{*}\right)<c \leq c_{2}\left(p^{*}\right) \\ p_{c}^{M} & \text { if } c>c_{2}\left(p^{*}\right)\end{cases}
$$

where $\tilde{p}$ solves (3). In this equilibrium consumers search for $c \leq c_{2}\left(p^{*}\right)$ and do not search otherwise.

The following figure illustrates the different regions mentioned in the previous proposition. If both $c$ and $s$ are low (the dark grey area), the downstream equilibrium price is given by the solution to (3). This is where firms charge a relatively low price and some consumers search while strictly preferring to do so. In the intermediate region (light grey area), where $c$ and $s$ are high but not too high, the firms charge a price, $\bar{p}$, that is just enough to guarantee that consumers continue to search if they find a low match value at the first firm they visited, but when they do so, their expected utility is zero. In this parameter range firms do not want to reduce their price because the marginal cost is too high and consumers do not search enough to warrant that, but they do not want to increase their price either as that would lead to consumers stopping to search, and a more elastic demand. In the region where both $c$ and $s$ are large (white area), firms charge the monopoly price and consumers do not search. This is the "Diamond" area.

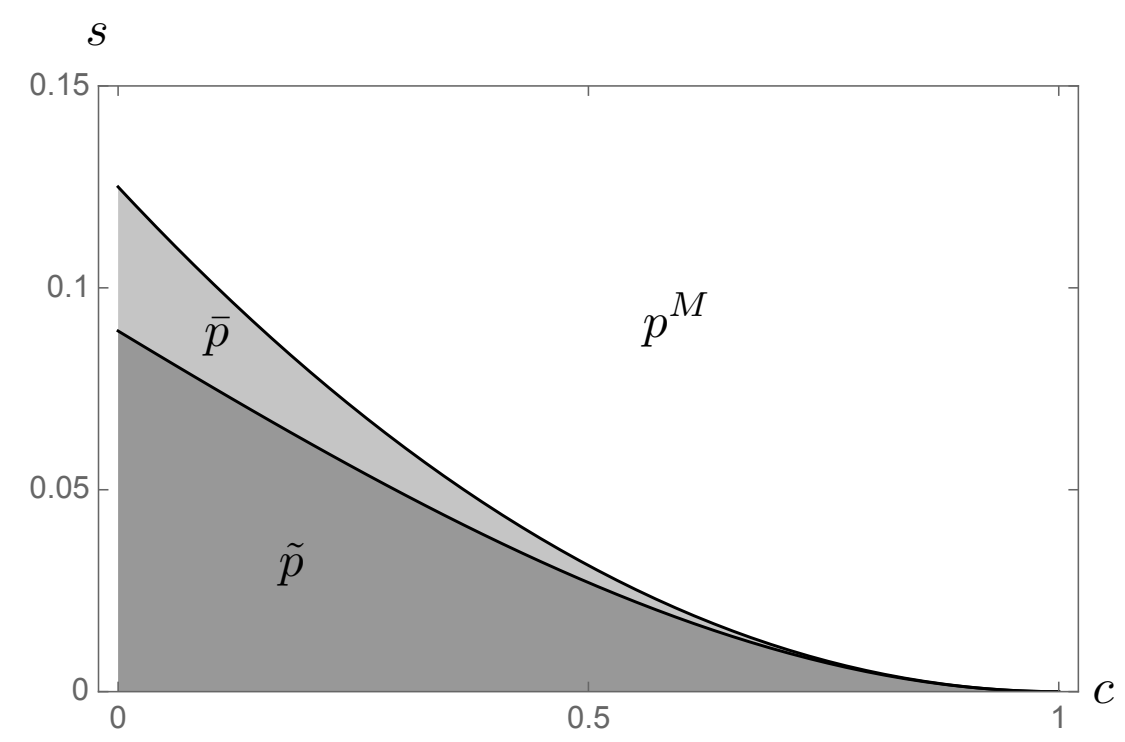

Figure 2: Equilibrium price depending on $s$ and $c$ for $G \sim U(0,1), \alpha=0$ and $p^{*}=0.6$. For a given marginal cost, there are two threshold levels of search cost that delimit the three possible pricing regimes. The same is true for a given $s$, provided that it is low enough.

Proposition 2 is important in explaining the role of consumer beliefs in cost-pass 


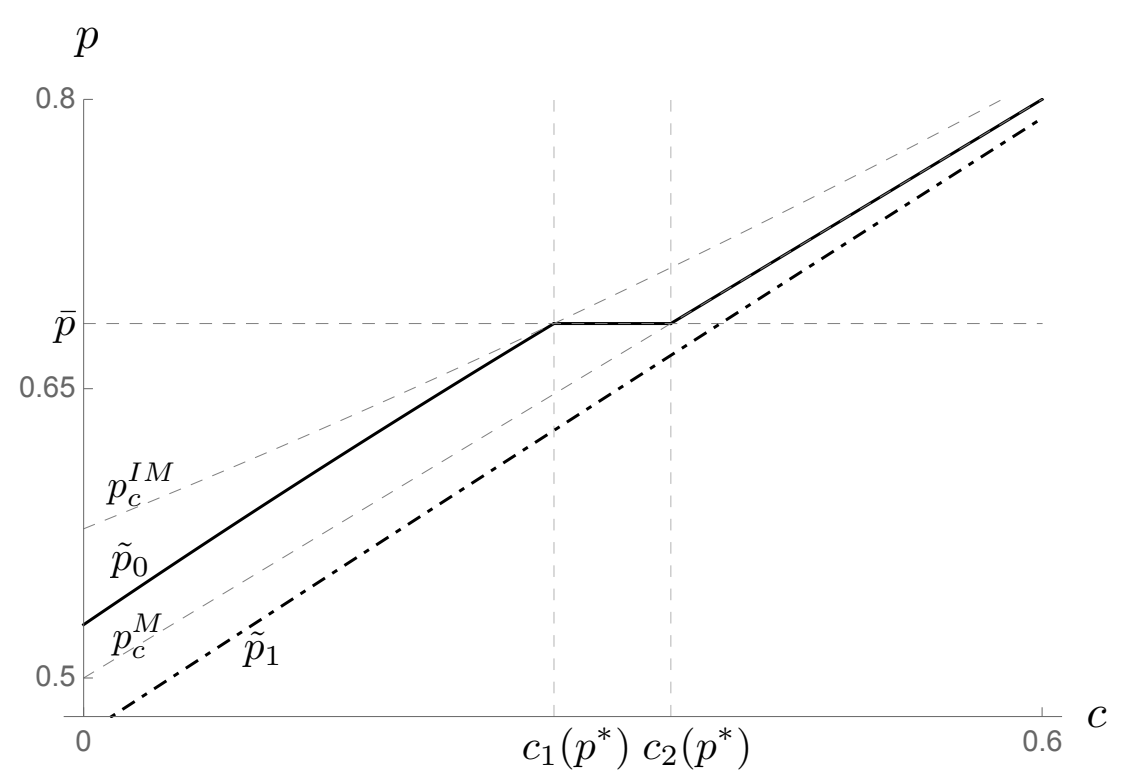

Figure 3: Downstream equilibrium price as a function of $c$ for $G \sim U(0,1), s=0.05$, $\alpha=0\left(\tilde{p}_{0}\right)$ and $\alpha=1\left(\tilde{p}_{1}\right)$. Solid line depicts $\tilde{p}$ for $\alpha=0$. For comparison, dot-dashed line depicts $\tilde{p}$ for $\alpha=1$. Thin dashed lines show $p_{c}^{M}$ and $p_{c}^{I M}$.

through. To see this, Figure 3 depicts prices $p(w)$ for the case where $\alpha=0$ and $\alpha=1$ (indicated by subscript on $\tilde{p}$ ) the utility draws are uniformly distributed on $[0,1]$ and the price $p^{*}$ consumers expect equals $0.5 .{ }^{11}$ For low levels of marginal cost, price is lower than the reservation utility. Once the price reaches the reservation utility level, which happens for intermediate marginal cost values, price is equal to the reservation utility, which does not depend on marginal cost. If the marginal cost is sufficiently high, the price exceeds the reservation utility and is equal to the monopoly price.

In contrast, if $\alpha=1$, the downstream model is identical to Wolinsky (1986). In this case $c_{1}\left(p^{*}\right)=c_{2}\left(p^{*}\right)$, so there are only two relevant cases in Proposition 2 governing downstream prices. Furthermore, given that $\bar{p}$ takes extreme value, only one case will be relevant, depending on whether $p^{*}$ is below or above $r$. In the figure $p^{*}<r$ so consumers search regardless of what price they observe. The equilibrium price $\tilde{p}_{1}$ is increasing in $c$ but unlike $\tilde{p}_{0}$ does not change regimes.

The important difference between the two curves is that if $\alpha=0$ (or more generally if $\alpha<1$ ), but not if $\alpha=1$, there is a region of cost levels where the downstream price is independent of the downstream firms' cost. Thus, the cost-pass through, of changes in $c$ on downstream prices critically depends on consumer beliefs. In our model where all consumers have the same search cost, downstream prices may be sticky with respect to changes in $c$. Finally, the intermediate region where prices are sticky exists for all values of $\alpha<1$, but as $\alpha$ increases and approaches 1 , the region shrinks to zero.

It is interesting to relate some aspects of this downstream equilibrium characterization

\footnotetext{
${ }^{11}$ The level of $p^{*}$ is unimportant when $\alpha=0$ so the solid line applies for all $p^{*}$.
} 
to the literature on sticky prices and incomplete cost pass-through. Starting with the seminal contributions by Sheshinski and Weiss (1977), Akerlof and Yellen (1985a,b) and Mankiw (1985), there is a large literature that explains why firms do not adjust prices following cost shocks assuming an exogenous cost of price adjustment, the menu cost. Our model generates price stickiness without assuming menu cost. Instead, prices are sticky because, for a range of marginal costs, firms find it optimal to set prices equal to the consumers' reservation utility that is independent of marginal cost. Sherman and Weiss (2015) empirically find that retailers in the Shuk Mahane Yehuda market in Jerusalem do not react to cost changes. They explain this finding with a dynamic model where consumers are not informed about the cost and do not adjust their expectations about prices charged by other retailers. In this world, if retailers were to increase their prices consumers would walk away to the next store. Compared to their paper, we have a static model with product differentiation where beliefs are endogenously specified. Cabral and Fishman (2012) have also proposed a search theoretic foundation for price stickiness. Their framework relies, however, on some stickiness in retailers' cost and they show that consumer search may lead to retail prices that are even stickier. Our Proposition 2 does not rely in any way on stickiness of retailers' cost. The result that prices are fully rigid does depend, however, on the assumption that all consumers have identical search costs. If search costs are heterogeneous (see, also, Moraga-González, Sándor and Wildenbeest (2017)), but the search cost distribution is concentrated around a certain value, prices will be "almost" sticky, and we would obtain a search theoretic explanation for incomplete cost pass-through (Weyl and Fabinger (2013)).

One can also describe the results on downstream pricing in relation to search cost $s$ for a given marginal cost $c$. It is clear from Figure 3, but also from a close inspection of the conditions in Proposition 2, that for a given $c$, there are two threshold levels of $s$, whereby if $s$ is smaller than the smallest threshold the price is $\tilde{p}$, if it is in between the two thresholds the price is $\bar{p}$, and if it is above the highest of the two threshold values, the price is $p_{c}^{M}$. The next corollary restates proposition 2 for a given $c$ by varying $s$. To this end, let $s_{1}\left(p^{*}\right)$ denote the search cost such that $c=\bar{p}-\frac{1-G(\bar{p})^{2}}{(\alpha+(2-\alpha) G(\bar{p})) g(\bar{p})}$, where $r$ (implicitly presented through its impact on $\bar{p}$ ) depends on $s$, and is strictly decreasing in $s$. Similarly, $s_{2}\left(p^{*}\right)$ solves $c=\bar{p}-\frac{1-G(\bar{p})}{g(\bar{p})}$.

Corollary 3. For given parameter values $c$ and $\alpha$ and a given consumer belief about the downstream price $p^{*}$, there exist $s_{1}\left(p^{*}\right)$ and $s_{2}\left(p^{*}\right)$ defined above, with $s_{1}\left(p^{*}\right) \leq s_{2}\left(p^{*}\right)$, such that

$$
p= \begin{cases}\tilde{p} & \text { if } s \leq s_{1}\left(p^{*}\right) \\ \bar{p} & \text { if } s_{1}\left(p^{*}\right)<s \leq s_{2}\left(p^{*}\right) \\ p_{c}^{M} & \text { if } s>s_{2}\left(p^{*}\right),\end{cases}
$$

Figure 4 illustrates corollary 3 emphasizing the role of consumer beliefs again. If $\alpha=1$, 
there are two cases as $s_{1}=s_{2} \cdot{ }^{12}$ If $s$ is small, the price is smaller than the monopoly price and increasing in $s$. For larger values of $s$, firms charge the monopoly price which is independent of $s$. For $\alpha=0$ (and any $\alpha<1$ ) there are three cases again. For low search costs, the price is increasing in the search cost and larger than when $\alpha=1$, but still small enough so that consumers continue to search if they encountered a low match value on their first search. As $r$ is decreasing in $s$, for $s=s_{1}$ we have $\tilde{p}=r$ and

$$
\tilde{p}=c+\frac{1-G(\tilde{p})^{2}}{2 g(\tilde{p}) G(\tilde{p})} .
$$

This price turns out to be the profit-maximizing price for a monopolist selling both products. Such a monopolist would set $p_{1}=p_{2}=p$ to maximize $\left(1-G(p)^{2}\right)(p-c)$. This is maximized at $p_{c}^{I M}$, which is implicitly defined by

$$
p_{c}^{I M}=c+\frac{1-G\left(p_{c}^{I M}\right)^{2}}{2 g\left(p_{c}^{I M}\right) G\left(p_{c}^{I M}\right)} .
$$

This price is always larger than the single-product monopoly price $p_{c}^{M}$ because the integrated monopolist takes into account demand externalities between the two products. Starting from $s_{1}$ the downstream equilibrium price is first equal to the reservation utility $r$, and as is this is decreasing in the search cost, downstream prices are decreasing in s. Therefore, for a range of search costs, the two firms set prices that are larger than the single-good monopoly price and that can be as high as the price of a multi-good monopolist. If the search cost is sufficiently high, firms charge the monopoly price and the price is again independent of $s$. Thus, for $\alpha=0$ (or in fact any $\alpha<1$ ) downstream price is non-monotonic in search cost.

As the joint profit maximizing result plays an important role in the next section, it is useful to explain it in more detail and to return to Figure 1. Consider a marginal upward deviation from $p_{i}=\bar{p}$ when $\bar{p}$ is close to $r$ (and $p_{i}^{e}=\bar{p}$ ). If $\alpha=0$, or equivalently $p_{j}^{e}=p_{i}$, firm $i$ does not trigger additional search by consumers who first visited this firm (as the lower bound of area $\mathrm{A}$ is $r$ and independent of $p_{i}$ ). Thus, an increase in $p_{i}$ only results in the shrinking of area $\mathrm{B}$, which when this area is very small is roughly equivalent to losing only those consumers whose valuations for $i$ are smaller than $p_{i}$, and at the same time whose valuations for $j$ are even lower. This is exactly the consideration of a joint profit maximizing monopolist considering whether to marginally upward deviating from $p_{i}=\bar{p}$ - when increasing $p_{i}$ it only loses consumers whose valuation for good $i$ is higher than for good $j$ : other consumers simply switch to the other good. Thus, for an appropriate

\footnotetext{
${ }^{12}$ The definitions of $s_{1}$ and $s_{2}$ make clear that they depend on $\alpha$. In the figure they are given for $\alpha=0$. If $\alpha=1$, we have that $s_{1}=s_{2}$, but in general these will be different from the critical search cost values for the case where $\alpha=0$. The Figure is calibrated such that for $\alpha=0$ the critical search cost value is equal to the value for $s_{2}$ when $\alpha=0$. This calibration also explains why for very small search costs, the price under $\alpha=1$ is larger than for $\alpha=0$.
} 


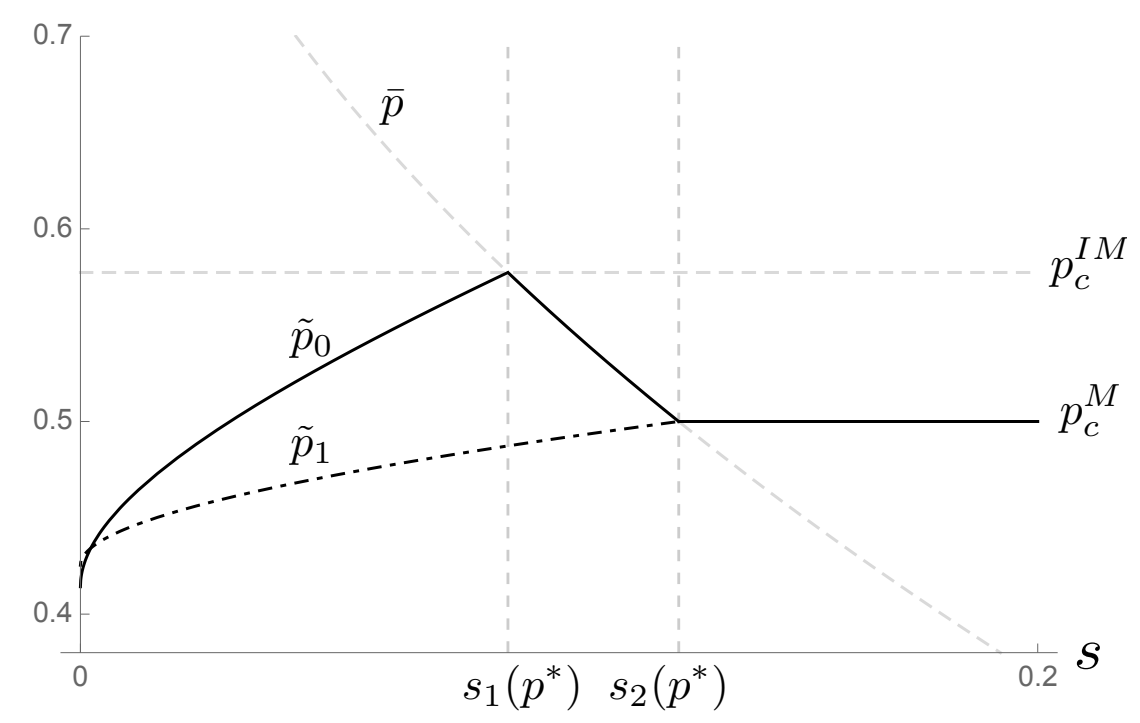

Figure 4: Downstream equilibrium price as a function of $s$ for $G \sim U(0,1), c=0$, and $p^{*}=0.5$. Solid line depicts $\tilde{p}$ for $\alpha=0$. For comparison, dot-dashed line depicts $\tilde{p}$ for $\alpha=1$.

choice of $s$, firms act as if they are jointly maximizing profits. It is surprising that a "collusive" outcome is achieved via consumer beliefs, while firms act independently, given these beliefs.

\section{$4 \quad$ Full Equilibrium Analysis}

With two-part tariffs, the upstream manufacturer maximizes total vertical industry profit subject to consumers' search behavior. In particular, conditional on consumers searching, the upstream firm would like to induce downstream firms to charge $p_{t}^{I M}$. This is the integrated monopoly price for two substitutes when the downstream marginal cost is $t$. It is clear that this equals the joint downstream profit maximizing price given the true marginal cost of the manufacturer (which is normalized to 0 ).

When the search cost $s$ is small enough such that $p_{t}^{I M} \leq r$, the upstream firm can safely induce $p_{t}^{I M}$ by charging an appropriate wholesale price $w$ and then extracting all of the downstream profits through $F$. The exact level of $w^{*}$ and $F^{*}$ depends on $s, t$ and $\alpha$. In particular, the upstream firm has to set $w^{*}$ such that $\tilde{p}\left(w^{*}\right)=p_{t}^{I M}$ for $\tilde{p}=p^{*}$ and then set $F^{*}=\left(1-G\left(p_{t}^{I M}\right)^{2}\right)\left(p_{t}^{I M}-c^{*}\right)$. Interestingly, even if $s=0$, the upstream manufacturer needs to charge $w^{*}>0$ as by themselves the downstream firms do not take into account the positive externality of a price increase on the demand of the substitute, and the positive effect this has for the manufacturer (as he sells anyway whether a consumer buys from one or the other retailer, and can set a higher fixed fee if retailers make more profits).

In order to find $w^{*}$, we have to take (3) and impose $p\left(w^{*}\right)=p^{*}$. The resulting pricing 
equation downstream is

$$
p^{*}-c=\frac{1-G\left(p^{*}\right)^{2}}{2 \int_{p^{*}}^{r} g(v)^{2} d v+2 g\left(p^{*}\right) G\left(p^{*}\right)+\alpha(1-G(r)) g(r)},
$$

Recall that the aim of the manufacturer is to make sure that retailers set $p^{*}=p_{t}^{I M}$, which gives the necessary wholesale price:

$$
w^{*}=p_{t}^{I M}-t-\frac{1-G\left(p_{t}^{I M}\right)^{2}}{2 \int_{p_{t}^{I M}}^{r} g(v)^{2} d v+2 g\left(p_{t}^{I M}\right) G\left(p_{t}^{I M}\right)+\alpha(1-G(r)) g(r)} .
$$

Thus, contrary to the traditional literature on vertical relations, where a manufacturer generally wants to avoid double marginalization by setting a wholesale price equal to its marginal cost, the manufacturer here wants to set a higher wholesale price to induce the retailers to implement the integrated monopoly price.

Potentially even more interesting is the case where $p_{t}^{I M}>r$. Here, the upstream manufacturer would still want to charge such a wholesale price $w$ that the downstream price is $p_{t}^{I M}$, but if consumers anticipate such a price, they will not search beyond the first firm, and in that case retailers would set a downstream price equal to $p_{c}^{M}$. If $\alpha<1$, the upstream firm may want, however, to affect consumer expectations concerning the downstream price through the indirect impact of $w$ on them (via the retail price charged). If consumers expect $w$ to be such that the downstream price is $r$, then retailers would set $p^{*}=r$. To acieve this, the upstream price $w$ should be set in such a way that the downstream equilibrium price satisfies $p(w)=r$. For this, $w$ should be such that $w \in\left[c_{1}-t, c_{2}-t\right]$ where $c_{i} \equiv c_{i}(r)$ and $c_{1}$ and $c_{2}$ are the lowest and highest marginal costs such that retailers would charge $r$ provided that consumers anticipate $p^{*}=r .{ }^{13}$ While there are many upstream prices that achieve the downstream price $r$, for each $w^{*}$ there is a unique optimal $F^{*}$ given by $F^{*}=\left(1-G(r)^{2}\right)\left(r-t-w^{*}\right)$.

In this case where $p_{t}^{I M}>r$, the upstream firm makes the vertical structure to "subsidize" search by inducing the downstream price to be equal to the reservation utility. For this to be an equilibrium, the upstream firm should indeed want to offer $\left(w^{*}, F^{*}\right)$. In principle, the upstream firm may want to deviate to $w>w^{*}$ because, conditional on consumers searching, it wants to induce the downstream price $p_{t}^{I M}$. However, if it does not adjust $F$ appropriately downstream firms will not participate. If $F$ is adjust appropriately, the manufacturer cannot make more profit for any $w \leq c_{2}-t$. If the manufacturer contemplates setting $w>c_{2}-t$, then consumers would adjust their beliefs upwards and stop searching. Thus any such deviation results in retailers choosing $p_{c}^{M}$ and consumers stopping at the first firm (if $\alpha<1$ ), resulting in a partial market breakdown. This argument continues to hold until $s$ or $t$ are large and it becomes unprofitable to sustain search through setting the downstream price at $r$. It is then more profitable to choose $w$ such

\footnotetext{
${ }^{13}$ Here, $c_{i}\left(p^{*}\right)$ are defined in the previous section with $p^{*}$ replacing $r$.
} 
that the downstream price is $p_{t}^{M}>r$, and no consumer searches beyond the first firm. By the definition of $p_{t}^{M}$, the upstream price that induces it is $w^{*}=0$.

Given the discussion above, we can characterize the pricing decision of the upstream manufacturer. For $\alpha<1$ we do this in a proposition characterizing the equilibrium in terms of $t$, while a corollary restates the result in terms of $s$. We then show (only for the characterization in terms of $t$ ) that the result is very different for $\alpha=1$. Finally, we analyze cost pass-through in the vertical industry structure.

Define $\underline{t}$ as the marginal cost at which the integrated monopoly price evaluated at the true production cost of the integrated monopolist is equal to the reservation utility. In other words, $\underline{t}$ is the solution to $p_{\underline{t}}^{I M}=r$ and write this condition as $\underline{t}=r-\frac{1-G(r)^{2}}{2 G(r) g(r)} \cdot{ }^{14}$ Further, implicitly define $\bar{t}$ as the solution to $\left(1-G(r)^{2}\right)(r-t)=\left(1-G\left(p_{t}^{M}\right)\right)\left(p_{t}^{M}-t\right)$, where the integrated monopolist would make the same profit if he induces the retailer to set $r$ or when he induces the retailers to set $p_{\bar{t}}^{M}$. In the proof we show this value exists and is unique, although it may be negative as well.

We can now state the main characterization of the overall equilibrium of the model. ${ }^{15}$

Proposition 4. For any $\alpha<1$ there exist threshold values of $t$, denoted by $\underline{t}$ and $\bar{t}$ with $\underline{t}<\bar{t}$, such that (i) if $t<\underline{t}$ the upstream manufacturer has a unique optimal wholesale price $w^{*}$ given in (7) and the downstream price is $p^{*}=p_{t}^{I M}$, (ii) if $t \in[\underline{t}, \bar{t}]$, any $w^{*} \in$ $\left[c_{1}(r)-t, c_{2}(r)-t\right]$ is optimal for the upstream manufacturer resulting in an equilibrium downstream price of $p^{*}=r$, and (iii) if $t>\bar{t}$, the optimal upstream price is $w^{*}=0$ resulting in an equilibrium downstream price of $p^{*}=p_{t}^{M}$.

Figure 5 illustrates our results. Before discussing the different equilibria themselves, we comment on the multiplicity of equilibria for $t \in(\underline{t}, \bar{t})$. The essential reason for the multiplicity is that in this region the upstream firm cannot have retailers charging $p_{t}^{I M}$ to consumers while simultaneously making sure that consumers search. It would rather have retail prices set at $r$ with consumers searching than induce the retailers to set a higher $p_{t}^{M}$ and consumers not searching. So $r$ is the preferred price. The upstream supplier can induce the downstream firms to set $r$ with multiple levels of $t$ as the downstream firms' profit function has a kink at $p=r$ when $p^{*}=r$. This type of multiplicity is not outcome-essential in that the profits of the upstream supplier, as well as who buys where and at what price are the same for all these equilibria. ${ }^{16}$

\footnotetext{
${ }^{14}$ The value $\underline{t}$ clearly exists (but it can be negative). The $\log$-concavity of $1-G(x)$ ensures that $\underline{t}$ is uniquely defined.

${ }^{15}$ The most interesting results described in the Proposition, namely those for $t<\bar{t}$, continue to hold for the case where the first search is costly. If $t>\bar{t}$ then consumers would not want to make the first search if it is costly and in that case, market break down is the only equilibrium outcome..

${ }^{16}$ For a subset of parameter values and if $0<\alpha<1$ another type of self-fulfilling "Diamond" equilibrium may exist, however. If $\alpha>0$ the manufacturer can only partially influence consumer expectations. The alternative equilibrium has consumers believe retail prices are high and given these beliefs the manufacturer can only induce consumers to search by inducing a very low $p(w)$, which may be unprofitable. For $\alpha=0$ the upstream firm has full control over beliefs and therefore can always "move" consumers to
} 


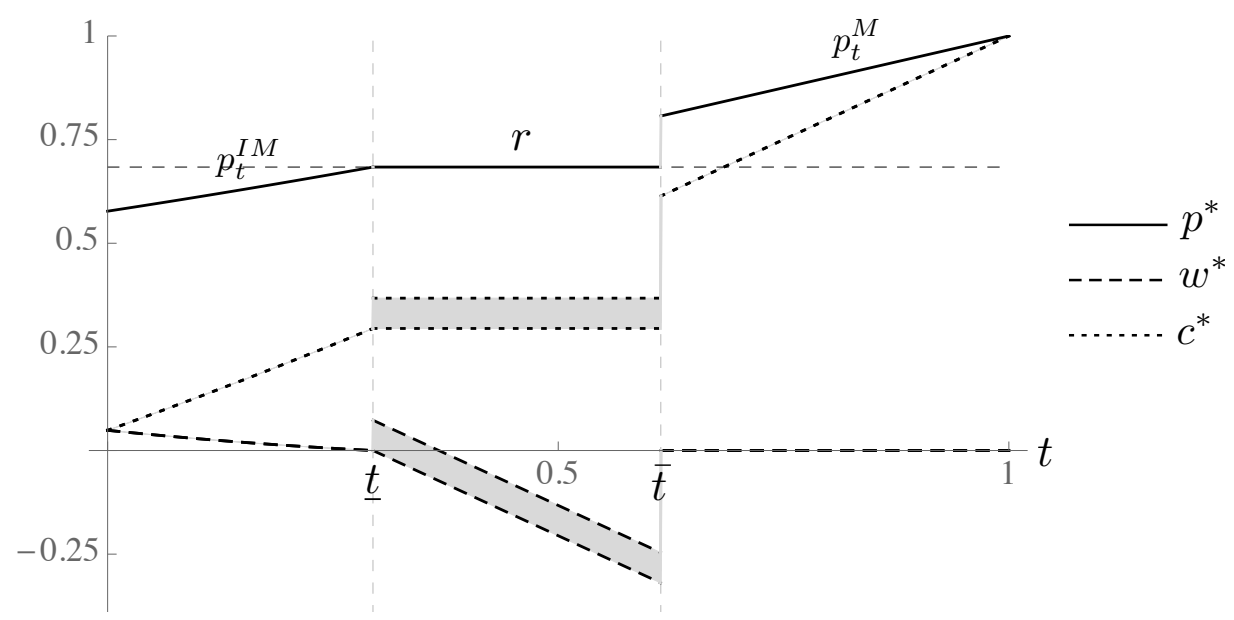

Figure 5: Downstream and upstream prices as the function of $t$ for $G \sim U(0,1), s=0.05$, and $\alpha=0$. Shaded areas correspond to upstream price multiplicity.

In the range of $t$ where the multiplicity is present, there always are equilibria where $w^{*}<0$. The reason should be clear: in this range the upstream firm has to subsidize search via very low unit price inducing downstream firms to charge $r$ and consumers to search the second time.

The upstream supplier does not directly control retail prices, however. Conditional on consumers searching, the supplier has an incentive to increase the retail price to $p^{I M}$. However, any deviation to $w>c_{2}(r)-t$ triggers a change in $p_{i}^{e}$ used by consumers. The result is that $p_{1}^{e}=p_{2}^{e}>r$ and consumers who draw $v_{i}$ below $r$ at the first firm expect negative utility from continuing to search and they stop searching. It is clear that $\alpha<1$ is essential to this: for passive beliefs $(\alpha=1)$ the supplier's temptation to deviate once consumers have made up their mind about searching (via $p^{*} \leq r$ ) is not restrained by anything, and therefore unavoidable. We will elaborate on the case where $\alpha=1$ below.

Note also how at $t=\underline{t}$, the optimal upstream supplier's price $w^{*}$ equals 0 , which is when downstream firms are able to charge the integrated monopoly price on their own. They are effectively able to "collude" aided by beliefs that discourage downward price deviations. This is true because $\alpha=0$ so a unit reduction in price induces consumers to believe that the firm they have not yet visited had also reduced its price by one unit. Such a highly collusive price is not feasible for any $\alpha>0$ because only a perfect combination of price-increase friendly beliefs and sufficiently high marginal cost allows retailers to charge the integrated monopoly price. When $t=\underline{t}$, by the definition of $\underline{t}, p^{*}=r$ therefore all the consumers who search are those who would not buy the good from the first firm they have visited. This means that firms are setting $p_{1}$ and $p_{2}$ knowing that the only consumers

the equilibrium where $p^{*}=r$. As beliefs become less responsive, the range where there is co-existence of Diamond equilibria without second search and equilibria were the downstream price equals $r$ grows. We do not focus on these equilibria as it is clear that these are not optimal from the monopoly manufacturer's point of view. Moreover, the range of parameter values for which these equilibria exist is not easily characterized. 
they are losing to the other firm are those who wouldn't buy from them anyway. This leads to the firms charging the integrated monopoly price. As the next figure illustrates in the context of the comparative statics with respect to the search cost $s$, for $\alpha=0.5$ the downstream firms are not able to charge $p_{t}^{I M}$ without the help of the upstream supplier. The supplier induces downstream firms to charge $p_{t}^{I M}$ by setting $w^{*}>0$.

We now restate this result in terms of search cost $s$. The key finding is that, because $r$ is inversely related to $s$, there may be a range of search costs where the equilibrium downstream price is decreasing in the search cost. Although we have found a similar pattern in our earlier paper on vertical relations in a search market with homogeneous goods (Janssen and Shelegia (2015)), the reason for this result is very different. In Janssen and Shelegia (2015) the mechanism is as follows: when consumers search for the lowest downstream price without knowing the upstream price, they have to blame downstream firms for price deviations above the reservation price, or else equilibrium would break down. ${ }^{17}$ This then makes the upstream firm wants to secretly deviate and eat up downstream margins. This incentive to secretly squeeze retailers results in excessively high equilibrium prices. The effect is mitigated when downstream firms have more market power and higher margins, i.e., when search costs are higher, so overall an increase in search costs may result in a downstream price reduction. In the current model, beliefs are key, and downstream price is decreasing in the search cost because when $\alpha<1$ the upstream firm is able to subsidize search via low upstream price (inducing retailers to follow suit choosing low downstream prices).

To state our next result more formally, implicitly define $\underline{s}$ and $\bar{s}$ in a similar way to $\underline{t}$ and $\bar{t}$, i.e., $\underline{s}$ is the search cost at which the integrated monopoly price evaluated at the true production cost of the integrated monopolist is equal to the reservation utility. Furthermore, implicitly define $\bar{s}$ to be the solution where the integrated monopolist would make the same profit if it induces the retailers to set $r$ compared to when it induces them to set $p_{t}^{M} \cdot{ }^{18}$

Corollary 5. For any $\alpha<1$ there exist threshold values of $s$, denoted by $\underline{s}$ and $\bar{s}$, with $\underline{s}<\bar{s}$, such that (i) if $s<\underline{s}$, the upstream manufacturer has a unique optimal wholesale price $w^{*}$ that is such that the downstream price is $p^{*}=p_{t}^{I M}$, (ii) if $s \in[\underline{s}, \bar{s}]$, any $w^{*} \in\left[c_{1}-t, c_{2}-t\right]$ is optimal for the upstream manufacturer resulting in an equilibrium downstream price of $r$, and (iii) if $s>\bar{s}$, the optimal upstream price is $w^{*}=0$ resulting in an equilibrium downstream price of $p_{t}^{M}$.

The proposition is illustrated in Figure 6 for $G \sim U(0,1), \alpha=0.5$ and $t=0.1$ where for preservation of space we depict $c^{*}=w^{*}+t$ instead of $w^{*}$. For low search costs the

\footnotetext{
${ }^{17}$ If consumers were to accept such prices, then downstream firms would indeed deviate and charge prices above the reservation price.

${ }^{18}$ Similar to the previous Proposition, results for $s<\bar{s}$ continue to hold for the case where the first search is costly.
} 


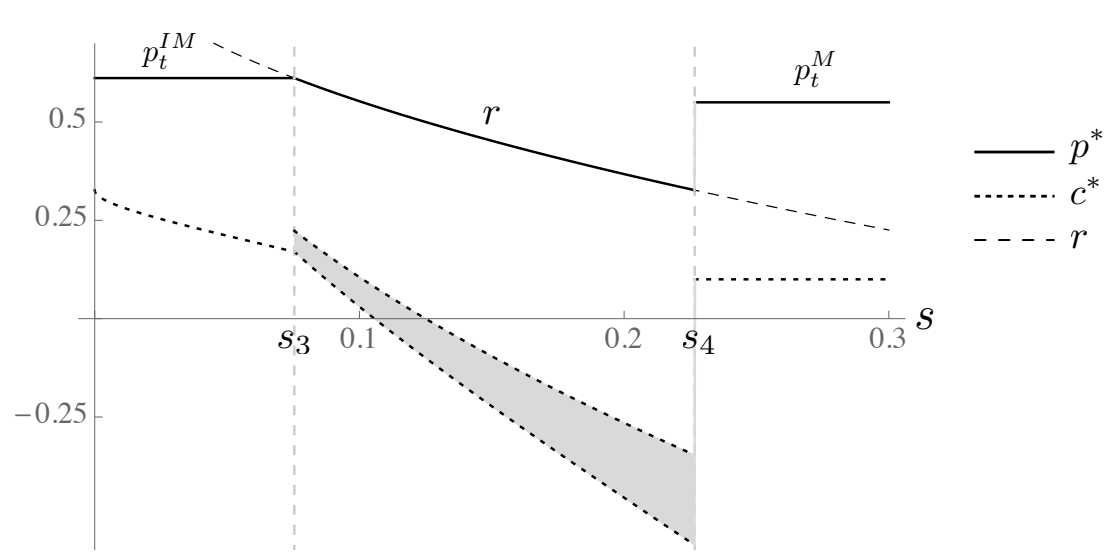

Figure 6: Downstream and upstream prices as the function of $s$ for $G \sim U(0,1), t=0.1$, and $\alpha=0.5$. Shaded areas correspond to upstream price multiplicity.

downstream price is constant, while the wholesale price is decreasing in $s$. This is because as $s$ increases, downstream margins grow and therefore the manufacturer does not need to push the downstream price as much up as it does for lower values of $s$. In the intermediate region of search costs the downstream price is equal to $r$ and therefore decreasing in $s$. To keep the downstream price at $r$, the manufacturer has to charge lower and lower wholesale prices, which may even become negative. For each $s$ in this region there are multiple values of the equilibrium $w^{*}$ because the downstream price as a function of $c$ is flat (as per Proposition 3). If $s$ is sufficiently high, the upstream firm no longer subsidizes search, and induces a single-good monopoly price that is above $r$. That is, even though the manufacturer is still able to prevent partial market breakdown, it is not in his interest to do so as he has to distort the retail price too much to make it possible.

It is interesting to observe that the two-part tariff we imposed is actually also the optimal contract in the general class of non-linear contracts. Industry profits are highest if retailers price at the integrated profit maximizing $p_{t}^{I M}$. With the nonlinear contract we specified, for $s<s_{1}(r)$ the manufacturer will set its wholesale price per unit $w$ such that retailers find it optimal to choose $r$ and extract all retailers' profit by choosing the fixed fee appropriately. For larger $s$, the manufacturer is constrained by retail and consumer behavior, but sets $w$ such that retail prices are as close as possible to $p_{t}^{I M}$ given these constraints.

Finally, we should note that the manufacturer does not have any incentive to foreclose one of the retailers by setting a contract the retailer will not accept. The main reason is that the manufacturer benefits from the diversity that is offered by the retailers, where different consumers prefer buying from different retailers creating more demand for the manufacturer than would be the case with only one retailer. Interestingly, a similar argument holds true for the question whether the manufacturer wants to sell through retailers at all, or prefers to sell directly. As long as retailers can create diversity that is difficult to replicate by one single manufacturer, where this diversity is important to 
attract different types of consumers that would otherwise not buy or not continue to search, the manufacturer benefits by selling through retailers.

We will now turn to the case where consumers exclusively blame downstream firms for deviations, i.e., $\alpha=1$, to show that this case is special. For this special case we need to define $\bar{t}^{\prime}=r-\frac{1-G(r)}{g(r)}$. This value represents the marginal cost for which the monopoly price $p_{t}^{M}$ is equal to the reservation utility. We then can state the following,

Proposition 6. For $\alpha=1$ there exist threshold values of $t$, denoted by $\underline{t}$ and $\bar{t}^{\prime}$ with $\underline{t}<\bar{t}^{\prime}$, such that (i) if $t<\underline{t}$ the upstream manufacturer has a unique optimal wholesale price $w^{*}$ that is such that the downstream price is $p^{*}=p_{t}^{I M}$, (ii) if $t \in\left[\underline{t}, \bar{t}^{\prime}\right)$, no pure strategy equilibrium exists, and (iii) if $t \geq \bar{t}^{\prime}$, the optimal upstream price is $w^{*}=0$ resulting in an equilibrium downstream price of $p^{*}=p_{t}^{M}$.

For small and large values of $t$, the equilibrium is essentially the same as for the case where $\alpha<1$. The important differences arise for intermediate levels of $t$. If $t<\underline{t}$ the downstream price and search behavior is identical, even though $w^{*}$ depends on $\alpha$ and is therefore different (higher) for $\alpha=1$. Unlike the case where $\alpha<1$, for $t \in\left(\underline{t}, \bar{t}^{\prime}\right)$ there is no pure strategy equilibrium if $\alpha=1$. In this range $t$ is so large that $p_{t}^{I M}$ exceeds $r$, but not too large so that $p_{t}^{M}$ is smaller than $r$. This means that if consumers expect $p^{*} \leq r$, then the upstream firm has an incentive (and ability) to induce $p_{t}^{I M}>r$, which is then inconsistent with $p^{*} \leq r$. If consumers do not search, then the optimal price for the upstream supplier is $w=0$ which induces $p_{t}^{M}$ downstream, but for $p^{*}=p_{t}^{M}$ consumers would search, invalidating the underlying assumption that $p_{t}^{M}$ is optimal for the upstream firm. This tension cannot be resolved in any pure strategy equilibrium. ${ }^{19}$ For $t>\bar{t}^{\prime}$ a pure strategy equilibrium where no consumer searches and downstream firms charge $p^{*}=p_{t}^{M}>r$ exists. Note that $\bar{t}^{\prime}<\bar{t}$ so that under $\alpha=1$ monopoly pricing starts at smaller $t$ values than if $\alpha<1$.Thus, we conclude that the case where $\alpha=1$ is not robust to small deviations in consumers beliefs: the intermediate region of $t$ values, where if $\alpha<1$ the manufacturer is able and willing to keep consumers interested in searching the second firm, is absent when $\alpha=1$. Instead, a pure strategy equilibrium does not exist and the threshold value of production cost $t$ where partial market breakdown starts is (much) smaller if $\alpha=1$. A similar comparison of the differences between the case $\alpha<1$ and $\alpha=1$ holds true in terms of the search cost parameter.

Finally, to see one of the important implications of our framework, let us consider cost pass-through for various levels of $t$. For $t<\underline{t}$ the retail price is equal to $p_{t}^{I M}$. Given the definition of $p_{t}^{I M}$, the pass-through defined as $\rho^{I M}=\frac{\partial p_{t}^{I M}}{\partial t}$ can be calculated using implicit differentiation. For $t>\bar{t}$ the price is the monopoly price, and again one can easily calculate the pass-through. For $t \in[\underline{t}, \bar{t}]$ pass-through is zero because the price is independent of cost.

\footnotetext{
${ }^{19}$ Mixed strategy equilibria may exist in this range. We do not attempt to characterize them as our focus is on the case where $\alpha<1$.
} 


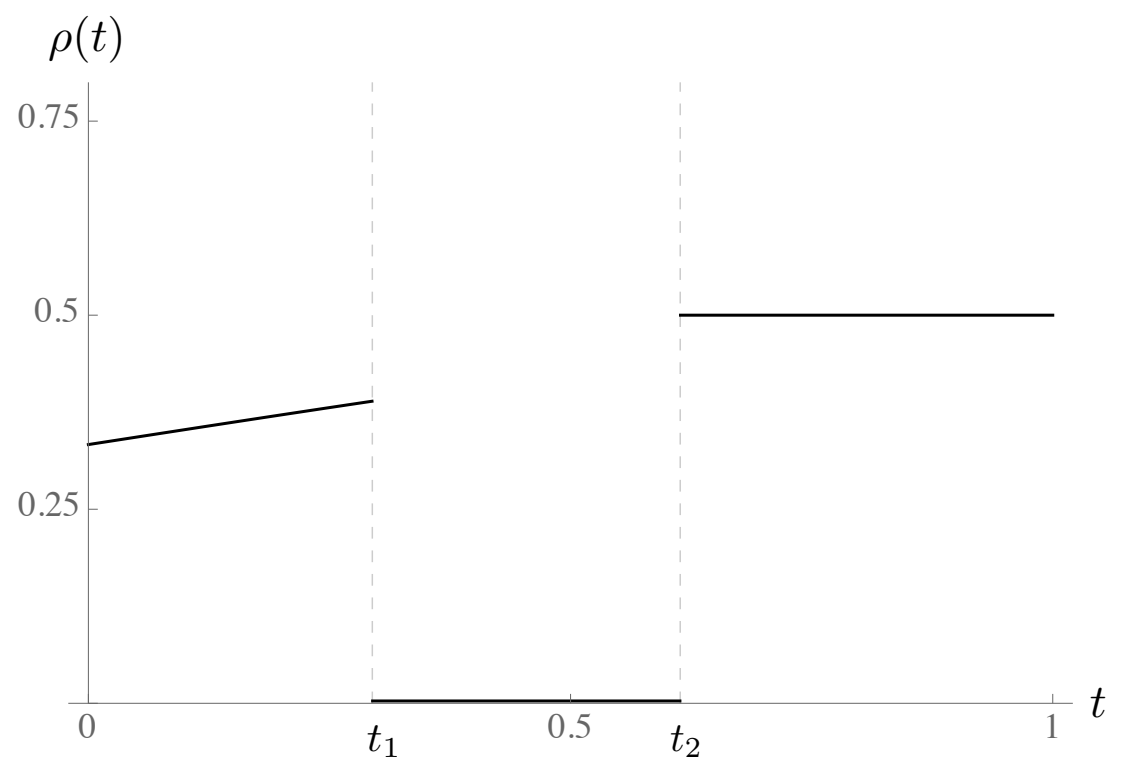

Figure 7: Cost passthrough for $G(v) \sim U(0,1), s=0.05$, and $\alpha=0$.

Proposition 7. Cost pass-through $\rho(t)$ is given by

$$
\rho(t)= \begin{cases}\frac{1}{2+\left(p_{t}^{I M}-t\right)\left(\frac{g^{\prime}\left(p_{t}^{I M}\right)}{g\left(p_{t}^{I M}\right)}+\frac{g\left(p^{I M}\right)}{G\left(p_{t}^{I M}\right)}\right)} & \text { if } t<\underline{t} \\ 0 & \text { if } \underline{t} \leq t \leq \bar{t} \\ \frac{1}{2+\left(p_{t}^{M}-t\right)\left(\frac{g^{\prime}\left(p_{t}^{I M}\right)}{g\left(p_{t}^{M}\right)}\right)} & \text { if } t>\bar{t},\end{cases}
$$

The figure below illustrates this result for the uniform distribution of match values. As can be seen, and as it is clear from evaluating the expressions in the Proposition for $g^{\prime}()=$.0 , the pass-through is smaller in markets with smaller cost. The reason is that in that case, the manufacturer adjust its wholesale price downwards in reaction to a cost change to keep the final retail price such that consumers search. Similarly, if we would have expressed the Proposition in terms of search cost, we would have that markets with high search costs would have higher pass-through rates than markets with smaller search costs. It is also clear that the pass-through rate is zero in markets with intermediate search costs. ${ }^{20}$

\section{Conclusion}

We see our contribution in this paper as twofold. First, we contribute to the methodology of the consumer search literature by explicitly focusing on the role of consumer beliefs on the optimal search rule and on market outcomes. We show that especially in a vertical

\footnotetext{
${ }^{20}$ One can show that if $g^{\prime}(v)$ is relatively low, passthrough is higher for the region where the monopoly price is charged than in the region where the integrated monopoly price is charged.
} 
market, this role is important. In particular, the standard assumption in the consumer search literature following Wolinsky (1986) is that, upon any observed price deviation, consumers believe that non-observed prices are equal to their equilibrium values. In the terminology of the vertical relations literature: consumers exclusively blame individual retailers they visited for observing an unexpected price. We show that the equilibrium predictions using this assumption are not robust to slight changes in beliefs: assuming that consumers attach a non-zero probability to the possibility that the upstream supplier's deviation is the cause of the unexpected retail price leads to qualitatively different results.

Second, using robust beliefs, we provide a number of new explanations for a range of different observations. For example, we show why the downstream (and wholesale) market price can be non-monotonic in search cost and independent of the marginal cost for a range of parameter values. We also show that retailers may price at the joint profit maximizing price even if they choose their pricing strategies in a noncooperative way. Finally, we show how our model with homogeneous search costs generates price rigidities in a natural way as firms have an incentive to charge prices so that consumers do not continue to search the next firm. This phenomenon occurs as the manufacturer has an incentive and the ability to pro-actively prevent a partial market breakdown by lowering its price. It is not difficult to see that for a small search cost heterogeneity (see, also, Moraga-González, Sándor and Wildenbeest (2014)) retail prices will not react much to changes in marginal cost. Many industries are characterized by incomplete cost passthrough (Weyl and Fabinger (2013)), i.e., higher wholesale prices induce lower margins at the retail level. In our model, low levels of cost pass-through arise because of retailers, but especially manufacturers, optimally reacting to consumer search.

Our model is purposefully simple in nature. We did not study retail oligopoly, or wholesale competition, or other arrangements (such as exclusive dealing) that are typically found in wholesale markets. We see our paper as building the foundations for a literature studying the implications of consumer search in a vertical supply channel. We have shown the basic issues to be addressed to understand pricing in the vertical channel. We have shown that these issues are nontrivial, and fundamentally different from when consumers have full information (as is typically the case in the vertical relations literature). In subsequent research other non-price issues that are important in the vertical relations literature can be added to the model we have outlined.

\section{References}

Akerlof, George A., and Janet L. Yellen. 1985a. "Can Small Deviations from Rationality Make Significant Differences to Economic Equilibria?" American Economic Review, 75(4): 708-720. 
Akerlof, George A., and Janet L. Yellen. 1985b. "A Near-rational Model of the Business Cycle, with Wage and Price Intertia." The Quarterly Journal of Economics, 100(5): 823-838.

Anderson, Simon P., and Regis Renault. 1999. "Pricing, Product Diversity, and Search Costs: A Bertrand-Chamberlin-Diamond Model." RAND Journal of Economics, 30(4): 719-735.

Anderson, Simon P., and Regis Renault. 2006. "Advertising Content." American Economic Review, 96(1): 93-113.

Armstrong, Mark, and Jidong Zhou. 2015. "Search deterrence." The Review of Economic Studies, 83(1): 26-57.

Armstrong, Mark, John Vickers, and Jidong Zhou. 2009. "Prominence and Consumer Search." The RAND Journal of Economics, 40(2): 209-233.

Asker, John, and Heski Bar-Isaac. 2017. "Vertical Information Restraints: Pro- and Anti-Competitive Impacts of Minimum Advertised Price Restrictions." Mimeo.

Bar-Isaac, Heski, Guillermo Caruana, and Vicente Cuñat. 2011. "Search, Design and Market Structure." American Economic Review, 102(2): 1140-60.

Cabral, Luís, and Arthur Fishman. 2012. "Business as Usual: A Consumer Search Theory of Sticky Prices and Asymmetric Price Adjustment." International Journal of Industrial Organization, 30(4): 371-376.

Diamond, Peter A. 1971. "A Model of Price Adjustment." Journal of Economic Theory, 3(2): 156-168.

Garcia, Daniel, Maarten C.W. Janssen, and Jun Honda. 2017. "The Double Diamond Paradox." AEJ Microeconomics, 9(3): 63-99.

Hart, Oliver, Jean Tirole, Dennis W. Carlton, and Oliver E. Williamson. 1990. "Vertical integration and Market Foreclosure." Brookings Papers on Economic Activity. Microeconomics, 205-286.

Janssen, Maarten C.W., and Sandro Shelegia. 2015. "Consumer Search and Double Marginalization." American Economic Review, 105(6): 1683-1710.

Janssen, Maarten C.W., José Luis Moraga-González, and Matthijs R. Wildenbeest. 2005. "Truly Costly Sequential Search and Oligopolistic Pricing." International Journal of Industrial Organization, 23(5-6): 451-466. 
Karle, Heiko, Martin Peitz, and Markus Reisinger. 2017. "Segmentation versus Agglomeration: Competition between Platforms with Competitive Sellers." Mimeo.

Lubensky, Dmitry. 2017. "A model of recommended retail prices." The RAND Journal of Economics, 48(2): 358-386.

Mankiw, N. Gregory. 1985. "Small Menu Costs and Large Business Cycles: A Macroeconomic Model of Monopoly." The Quarterly Journal of Economics, 100(2): 529-538.

McAfee, R. Preston, and Marius Schwartz. 1994. "Opportunism in Multilateral Vertical Contracting: Nondiscrimination, Exclusivity, and Uniformity." American Economic Review, 84(1): 210-30.

Moraga-González, José Luis, Zsolt Sándor, and Matthijs R. Wildenbeest. 2014. "Prices, Product Differentiation, And Heterogeneous Search Costs."

Moraga-González, José Luis, Zsolt Sándor, and Matthijs R Wildenbeest. 2017. "Prices and Heterogeneous Search Costs." The RAND Journal of Economics, 48(1): 125-146.

Sherman, Joshua, and Avi Weiss. 2015. "Price Response, Asymmetric Information and Competition." The Economic Journal, 125(589): 2077-2115.

Sheshinski, Eytan, and Yoram Weiss. 1977. "Inflation and Costs of Price Adjustment." Review of Economic Studies, 44(2): 287-303.

Stahl, Dale O. 1989. "Oligopolistic Pricing with Sequential Consumer Search." American Economic Review, 79(4): 700-712.

Wang, Chengsi, and Julian Wright. 2017. "Search Platforms: Showrooming and Price Parity Clauses." Mimeo.

Weyl, E Glen, and Michal Fabinger. 2013. "Pass-through as an Economic Tool: Principles of Incidence Under Imperfect Competition." Journal of Political Economy, 121(3): 528-583.

Wolinsky, Asher. 1986. "True Monopolistic Competition as a Result of Imperfect Information." Quarterly Journal of Economics, 101(3): 493-511.

Zhou, Jidong. 2014. "Multiproduct search and the joint search effect." The American Economic Review, 104(9): 2918-2939. 


\section{Appendix: Proofs}

Proposition 1. If the utility distribution $G(v)$ is uniformly distributed on $[0,1]$, then a symmetric downstream equilibrium exists and is unique.

Proof. Consider the match function to be the uniform distribution over [0,1]. We first prove the strict concavity of the profit function when $p_{i}<\bar{p}$. We distinguish two cases: (i) $p_{j}<\bar{p}$ and (ii) $p_{j}>\bar{p}$.

In the first case the demand $q_{i}\left(p_{i}, p_{j}, p^{*}\right)$ of firm $i$ observing $w \neq w^{*}$ and setting price $p_{i}$ believes the other firm sets $p_{j}=p(w)$ while the ex ante consumer expectation of prices is $p^{*}$, is given by the four components in Figure 1 where we set $p_{j}^{e}=\alpha p^{*}+(1-\alpha) p_{i}$ and $p_{i}^{e}=\alpha p^{*}+(1-\alpha) p_{j}$. Thus, (assuming the regions are not empty) the size of the four regions being $A, B, C$ and $D$ is equal to, respectively

$$
\begin{aligned}
& 1-r+\alpha\left(p^{*}-p_{i}\right) \\
& \left(r-\alpha p^{*}-(1-\alpha) p_{i}\right)\left(p_{j}+\frac{1}{2}\left(r-\alpha p^{*}-(1-\alpha) p_{i}\right)\right) \\
& \left.\left[1-r-p_{i}+\alpha p^{*}+(1-\alpha) p_{j}\right)\right]\left(r-\alpha\left(p^{*}-p_{j}\right)\right) \\
& \left.\left[r-\alpha p^{*}-(1-\alpha) p_{j}\right)\right]\left(p_{j}+\frac{1}{2}\left(r-\alpha\left(p^{*}-p_{j}\right)-p_{j}\right)\right) .
\end{aligned}
$$

Thus, the profit function $\pi_{i}=q_{i}\left(p_{i}, p_{j}, p^{*}\right)\left(p_{i}-c\right)$ is concave if $\partial^{2} \pi_{i} / \partial p_{i}^{2}=2 \partial q_{i}\left(p_{i}, p_{j}, p^{*}\right) / \partial p_{i}+$ $\left(p_{i}-c\right) \partial q_{i}^{2}\left(p_{i}, p_{j}, p^{*}\right) / \partial p_{i}^{2}<0$, where we have to take into account that $\partial p_{j}^{e} / \partial p_{i}=(1-\alpha)$ as $p_{j}^{e}=\alpha p^{*}+(1-\alpha) p_{i}$. As

$$
\begin{aligned}
\frac{\partial q_{i}\left(p_{i}, p_{j}, p^{*}\right)}{\partial p_{i}} & =-\alpha-(1-\alpha)\left(p_{j}+r-\alpha p^{*}-(1-\alpha) p_{i}\right)-\left(r-\alpha\left(p^{*}-p_{j}\right)\right) \\
& =-\alpha+(1-\alpha)^{2} p_{i}-(2-\alpha)\left(r-\alpha p^{*}\right)-p_{j}
\end{aligned}
$$

and

$$
\frac{\partial q_{i}^{2}\left(p_{i}, p_{j}^{e}, p^{*}\right)}{\partial p_{i}^{2}}=(1-\alpha)^{2}
$$

Thus,

$$
\partial^{2} \pi_{i} / \partial p_{i}^{2}=2\left[-\alpha+(1-\alpha)^{2} p_{i}-(2-\alpha)\left(r-\alpha p^{*}\right)-p_{j}\right]+(1-\alpha)^{2}\left(p_{i}-c\right) .
$$

As $p_{i}-c<p_{i}<\bar{p}=\frac{r-\alpha p^{*}}{1-\alpha}$ it is clear that this expression is smaller than

$$
\begin{aligned}
& 2\left[-\alpha+(1-\alpha)\left(r-\alpha p^{*}\right)-(2-\alpha)\left(r-\alpha p^{*}\right)-p_{j}\right]+(1-\alpha)\left(r-\alpha p^{*}\right) \\
= & -2\left[\alpha+\left(r-\alpha p^{*}\right)+p_{j}\right]+(1-\alpha)\left(r-\alpha p^{*}\right)<0
\end{aligned}
$$

Hence, the profit function is strictly concave for $p_{i}<\bar{p}$ and $p_{j}<\bar{p}$.

Consider next the case where $p_{j}>\bar{p}$. in this case, firm $i$ does not attract any consumer 
who first visited firm $j$ as these consumers believe that firm $i$ sets such a high price that it is not worthwhile to incur the search cost $s$. Thus, only regions $A$ and $B$ are relevant for consumer demand. In this case, using $p_{i}-c<p_{i}<\bar{p}=\frac{r-\alpha p^{*}}{1-\alpha}$ and $p_{j}>\bar{p}$ we have

$$
\begin{aligned}
\partial^{2} \pi_{i} / \partial p_{i}^{2} & =2\left[-\alpha-(1-\alpha)\left(r-\alpha p^{*}-(1-\alpha) p_{i}\right)-(1-\alpha) p_{j}\right]+(1-\alpha)^{2}\left(p_{i}-c\right) \\
& <2\left[-\alpha-(1-\alpha) p_{j}\right]+(1-\alpha)\left(r-\alpha p^{*}\right) \\
& <-2 \alpha-(1-\alpha) p_{j}-\alpha\left(r-\alpha p^{*}\right)<0 .
\end{aligned}
$$

Thus, we have now proved that the profit function is strictly concave for $p_{i}<\bar{p}$.

Next consider prices such that $p_{i}>\bar{p}$. In this case as $\bar{p}=\frac{r-\alpha p^{*}}{1-\alpha}$ we have that $p_{i}>$ $r-\alpha\left(p^{*}-p_{i}\right)$ such that region $\mathrm{B}$ is empty: firm $i$ does not get any returning consumers as no consumer who first visited firm $i$ continues to search firm $j$ in the first place. Again, we have to distinguish two cases: (i) $p_{j}<\bar{p}$ and (ii) $p_{j}>\bar{p}$.

If $p_{j}<\bar{p}$, then firm $i$ receives demand from regions $A, C$ and $D$. Thus,

$$
\frac{\partial q_{i}\left(p_{i}, p_{j}, p^{*}\right)}{\partial p_{i}}=-\alpha-\left(r-\alpha\left(p^{*}-p_{j}\right)\right)
$$

and

$$
\partial^{2} \pi_{i} / \partial p_{i}^{2}=2\left[-\alpha-\left(r-\alpha p^{*}\right)-\alpha p_{j}\right]+(1-\alpha)^{2}\left(p_{i}-c\right)
$$

This expression is clearly increasing in $p_{i}$, while it is negative at $p_{i}=\bar{p}$. Thus, either $\partial^{2} \pi_{i} / \partial p_{i}^{2}<0$ for all values of $p_{i}$ or there is a cut-off value for $p_{i}$ such that for larger values $\partial^{2} \pi_{i} / \partial p_{i}^{2}>0$, while for smaller values it is negative. In the former case the profit function is strictly concave, while in the latter case it is strictly quasi-concave due to the fact that $q_{i}\left(1, p_{j}, p^{*}\right)=0$, while $q_{i}\left(p_{i}, p_{j}, p^{*}\right)>0$ for all $p_{i}<1$.

If $p_{j}>\bar{p}$, then firm $i$ effectively also does not get any demand from consumers who first visited firm $j$. Demand is therefore $\left(1-G\left(p_{i}\right)\right)=1-p_{i}$ and it is clear the profit function is strictly concave.

Finally, we need to establish that for any given $p_{j}$ the overall profit function is (at least) strictly quasi-concave. We show that for each $p_{j}$ the left-hand side derivative of the profit function at $p_{i}=\bar{p}$ is larger than or equal to the right-hand side derivative of the profit function, i.e., $\lim _{p_{i} \uparrow \bar{p}} \partial \pi_{i} / \partial p_{i}>\lim _{p_{i} \downarrow \bar{p}} \partial \pi_{i} / \partial p_{i}$. Together with the strict concavity of the profit function for $p_{i}<\bar{p}$ and the strict (quasi-)concavity for $p_{i}>\bar{p}$ (and $\lim _{p_{i} \downarrow \bar{p}} \partial^{2} \pi_{i} / \partial p_{i}^{2}<0$ if $p_{j}<\bar{p}$ ) this establishes the overall strict quasiconcavity of the profit function. Consider $p_{j} \leq \bar{p}$ first. We have seen above that the demand for firm $i$ comprises the areas $C$ and $D$, independent of whether or not $p_{I}<\bar{p}$. Thus, if there is a difference in the left- and right-hand derivatives it should be relative to the demand regions $A$ and $B$. Similarly, if we consider $p_{j}>\bar{p}$, then anyway only the demand regions $A$ and $B$ are relevant as no consumer that first visited firm 
$j$ would visit firm $i$. Thus, independent of whether or not $p_{j} \leq \bar{p}$ we only need to establish that $\lim _{p_{i} \uparrow \bar{p}} \partial q_{i}\left(p_{i}, p_{j}, p^{*}\right) / \partial p_{i} \geq \lim _{p_{i} \downarrow \bar{p}} \partial q_{i}\left(p_{i}, p_{j}, p^{*}\right) / \partial p t_{i}$ as $\partial \pi_{i} / \partial p_{i}=\left(p_{i}-\right.$ c) $\partial q_{i}\left(p_{i}, p_{j}, p^{*}\right) / \partial p_{i}+q_{i}\left(p_{i}, p_{j}, p^{*}\right)$ and $\lim _{p_{i} \uparrow \bar{p}} q_{i}\left(p_{i}, p_{j}, p^{*}\right)=\lim _{p_{i} \downarrow \bar{p}} q_{i}\left(p_{i}, p_{j}, p^{*}\right)$. It is clear that $\lim _{p_{i} \uparrow \bar{p}} \partial q_{i}\left(p_{i}, p_{j}, p^{*}\right) / \partial p_{i}=-G\left(r+p_{j}-\alpha p^{*}-(1-\alpha) p_{i}\right)-\alpha g\left(r-\alpha\left(p^{*}-p_{i}\right)\right)(1-$ $\left.G\left(r+p_{j}-\alpha p^{*}-(1-\alpha) p_{i}\right)\right) \geq-1$, whereas $\lim _{p_{i} \downarrow \bar{p}} \partial q_{i}\left(p_{i}, p_{j}, p^{*}\right) / \partial p_{i}=-1$. Thus, for any utility distribution function $G($.$) the left-hand side derivative of the profit function$ at $p_{i}=\bar{p}$ is larger than or equal to the right-hand side derivative of the profit function. If the inequality is strict, there is a kink in the profit function.

As the profit function is strictly quasi-concave in $p_{i}$ the best response function $p_{i}\left(p_{j} ; p^{*}, c\right)$ is well defined for each value of consumer expectation $p^{*}$ and each value of the firm's cost $c$. As the profit function $\pi_{i}=q_{i}\left(p_{i}, p_{j}, p^{*}\right)\left(p_{i}-c\right)$ is continuous in $p_{i}$ and $p_{j}$ the best response functions are also continuous and a standard fixed point argument then establishes the existence of a symmetric equilibrium.

Uniqueness of a symmetric equilibrium follows from the following considerations. First, within the two regions $p_{i}=p_{j}<\bar{p}$ and $p_{i}=p_{j}>\bar{p}$ an equilibrium is unique if the slope of the best response function

$$
\frac{d p_{i}}{d p_{j}}=-\frac{\partial^{2} \pi_{i} / \partial p_{i} \partial p_{j}}{\partial^{2} \pi_{i} / \partial p_{i}^{2}}<1
$$

In the region $p_{i}=p_{j}<\bar{p}$,

$$
\begin{aligned}
\partial^{2} q_{i} / \partial p_{j}= & \left.(1-\alpha)\left(r-\alpha\left(p^{*}-p_{j}\right)\right)+\alpha\left[1-r-p_{i}+\alpha p^{*}+(1-\alpha) p_{j}\right)\right] \\
& \left.-\frac{1}{2}(1-\alpha)\left(p_{j}+\left(r-\alpha\left(p^{*}-p_{j}\right)\right)\right)+\frac{1}{2}(1-\alpha)\left[r-\alpha p^{*}-(1-\alpha) p_{j}\right)\right] \\
= & (1-\alpha)^{2}\left(\bar{p}-p_{j}\right)+\alpha\left(1-p_{i}\right) .
\end{aligned}
$$

Thus, as $\partial^{2} \pi_{i} / \partial p_{i} \partial p_{j}=\partial q_{i}\left(p_{i}, p_{j}, p^{*}\right) / \partial p_{j}+\left(p_{i}-c\right) \partial q_{i}^{2}\left(p_{i}, p_{j}, p^{*}\right) / \partial p_{i} \partial p_{j}, \frac{d p_{i}}{d p_{j}}<1$ if , and only if,

$$
\begin{aligned}
& (1-\alpha)^{2}\left(\bar{p}-p_{j}\right)+\alpha\left(1-p_{i}\right)-\left(p_{i}-c\right) \\
< & 2\left[\alpha-(1-\alpha)^{2} p_{i}+(2-\alpha)\left(r-\alpha p^{*}\right)+p_{j}\right]-(1-\alpha)^{2}\left(p_{i}-c\right)
\end{aligned}
$$

As in a symmetric equilibrium $p_{i}=p_{j}$ this reduces to

$$
\left(\bar{p}-p_{i}\right)+\alpha\left(1-p_{i}\right)<\alpha(2-\alpha)\left(p_{i}-c\right)+2 \alpha+2(2-\alpha) \bar{p}
$$

which is always the case.

Clearly, as in the region $p_{i}=p_{j}>\bar{p}, \partial^{2} \pi_{i} / \partial p_{i} \partial p_{j}=0$ and there is a unique monopoly price, there can only be a unique equilibrium in this region.

Proposition 2. For given parameter values $s$ and $\alpha$ and a given consumer belief about 
the downstream price $p^{*}$ the symmetric downstream equilibrium price $p(w)$ is given by

$$
p(w)= \begin{cases}\tilde{p} & \text { if } c \leq c_{1}\left(p^{*}\right) \\ \bar{p} & \text { if } c_{1}\left(p^{*}\right)<c \leq c_{2}\left(p^{*}\right) \\ p_{c}^{M} & \text { if } c>c_{2}\left(p^{*}\right)\end{cases}
$$

where $\tilde{p}$ solves (3). In this equilibrium consumers search for $c \leq c_{2}\left(p^{*}\right)$ and do not search otherwise.

Proof. Let us start with $c>c_{2}\left(p^{*}\right)$. We first establish that $p=p_{c}^{M}$ is indeed an equilibrium. If firm $j$ charges $p_{j}=p_{c}^{M}$ then firm $i$ does not receive any second visits from $j$ because by definition of $c_{2}\left(p^{*}\right)$ we have $p_{c}^{M}>\bar{p}$ and therefore consumers arriving to $j$ set $p_{i}^{e}>r$ and do not search. Given that no second visits occur, firm $i$ cannot do better than to charge the monopoly price, and sell to all consumers who arrive to it. In this case, consumers who make first visits to $i$ will not search either, giving $i$ (maximum possible) monopoly profits. Having verified that $p_{i}=p_{j}=p_{c}^{M}$ is an equilibrium, we now show that no other equilibrium exists. Assume the equilibrium price $p$ satisfies $p>\bar{p}$ but $p \neq p_{c}^{M}$. This cannot be an equilibrium because no consumers search, and therefore each firm is better off charging the monopoly price $p_{c}^{M}$. Assume now that $p \leq \bar{p}$. In such equilibrium consumers would search. Conditional on consumers searching $\left(I_{r \geq p_{i}^{e}}=1\right)$ the symmetric equilibrium price has to satisfy (3). Moving the RHS to the left and taking derivative with respect to $p$ reveals that the derivative is positive by log-concavity of $1-G(x)$. Plugging $\bar{p}$ instead of $p$ yields $\bar{p}-\frac{1-G(\bar{p})^{2}}{(\alpha+(2-\alpha) G(\bar{p})) g(\bar{p})}-c$, which is negative by $c>c_{2}\left(p^{*}\right) \geq c_{1}\left(p^{*}\right)$ and the definition of $c_{1}\left(p^{*}\right)$. It is therefore impossible that $p$ that solves (3) simultaneously satisfies $p<\bar{p}$.

Assume now that $c<c_{1}\left(p^{*}\right)$. Given that consumers search, the symmetric equilibrium price has to be $\tilde{p}$. For this to be true, we need that $\tilde{p} \leq \bar{p}$. This follows using similar steps as above. If consumers do not search, then both firms aught to charge $p_{c}^{M}$, but $c<$ $c_{1}\left(p^{*}\right) \leq c_{2}\left(p^{*}\right)$ and therefore $p_{c}^{M}<\bar{p}$ so consumers would search in such an equilibrium, a contradiction.

Finally, assume $c_{1}\left(p^{*}\right)<c \leq c_{2}\left(p^{*}\right)$. First let us prove that $p=\bar{p}$ is indeed an equilibrium. Assume firm $j$ charges $p_{j}=\bar{p}$. Then for firm $i$ demand is given by

$$
\begin{aligned}
& q_{i}\left(p_{i}, p_{j}, p^{*}\right)=\left(1-G\left(p_{i}+\max \left\{r-p_{j}^{e}, 0\right\}\right)\right)+\int_{p_{i}}^{p_{i}+\max \left\{r-p_{j}^{e}, 0\right\}} G\left(p_{j}-p_{i}+v\right) g(v) d v \\
& +G\left(p_{j}\right)\left(1-G\left(p_{i}\right)\right)
\end{aligned}
$$

Assume that $p_{i} \leq \bar{p}$ so that consumers who visit $i$ first and draw low utility go on to search $j$, and then evaluate the derivative of profit of $i$ at $p_{i}=\bar{p}$, to get $\frac{\partial \pi_{i}}{\partial p_{i}}\left(p_{i}=\bar{p}\right)=$ 
$(\bar{p}-c) g(\bar{p})((1-a) G(\bar{p})+a+G(r))+(1-G(\bar{p}))(1+G(r))>0$, which by concavity of profits to the left of $\bar{p}$ means that the maximizer cannot be $p_{i}<\bar{p}$. Now assume $p_{i}>\bar{p}$. In this region the profit is proportional to the monopoly one, and is therefore maximized at $p_{c}^{M}$. By the definition of $c_{2}\left(p^{*}\right), p_{c}^{M}<\bar{p}$, therefore the profit is decreasing for all $p>\bar{p}$ and is again maximized at $\bar{p}$. That no equilibrium with $p<\bar{p}$ can exist follows from $c>c_{1}\left(p^{*}\right)$ and similar steps as above. For $p>\bar{p}$ there would be no search, so both firms would optimally charge $p_{c}^{M}$ which by $c<c_{2}\left(p^{*}\right)$ contradicts $p>\bar{p}$.

Corollary 3. For given parameter values $c$ and $\alpha$ and a given consumer belief about the downstream price $p^{*}$, there exist $s_{1}\left(p^{*}\right)$ and $s_{2}\left(p^{*}\right)$ defined above, with $s_{1}\left(p^{*}\right) \leq s_{2}\left(p^{*}\right)$, such that

$$
p= \begin{cases}\tilde{p} & \text { if } s \leq s_{1}\left(p^{*}\right) \\ \bar{p} & \text { if } s_{1}\left(p^{*}\right)<s \leq s_{2}\left(p^{*}\right) \\ p_{c}^{M} & \text { if } s>s_{2}\left(p^{*}\right),\end{cases}
$$

Proof. Proof follows essentially the same steps as the proof of Proposition 3. This is because $r$ is strictly decreasing in $s$ which means that $\bar{p}$ is also strictly decreasing in $s$. It is therefore true that $s \leq s_{1}\left(p^{*}\right)$ iff $c<c_{1}\left(p^{*}\right), s_{1}\left(p^{*}\right)<s \leq s_{2}\left(p^{*}\right)$ iff $c_{1}\left(p^{*}\right)<c \leq c_{2}\left(p^{*}\right)$ and $s>s_{2}\left(p^{*}\right)$ iff $c>c_{2}\left(p^{*}\right)$. Once this is established, the proof of Proposition 3 suffices.

Proposition 4. For any $\alpha<1$ there exist threshold values of $t$, denoted by $\underline{t}$ and $\bar{t}$ with $\underline{t}<\bar{t}$, such that (i) if $t<\underline{t}$ the upstream manufacturer has a unique optimal wholesale price $w^{*}$ given in (7) and the downstream price is $p^{*}=p_{t}^{I M}$, (ii) if $t \in[\underline{t}, \bar{t}]$, any $w^{*} \in\left[c_{1}(r)-t, c_{2}(r)-t\right]$ is optimal for the upstream manufacturer resulting in an equilibrium downstream price of $p^{*}=r$, and (iii) if $t>\bar{t}$, the optimal upstream price is $w^{*}=0$ resulting in an equilibrium downstream price of $p^{*}=p_{t}^{M}$.

Proof. Let us first prove that $\underline{t}$ and $\bar{t}$ and are uniquely defined. For $\underline{t}$ existence and uniqueness is trivial. For $\bar{t}$ note that $\left(1-G(r)^{2}\right)(r-t)=\left(1-G\left(p_{t}^{M}\right)\right)\left(p_{t}^{M}-t\right)$, can only hold for $p_{t}^{M}>r$, which then means that where it holds $\left(1-G(r)^{2}\right)>\left(1-G\left(p_{t}^{M}\right)\right)$. The derivative of the LHS is $-\left(1-G(r)^{2}\right)$, and of the RHS is $-\left(1-G\left(p_{t}^{M}\right)\right)$. Therefore, if the equation holds for some $t$, given that $\left(1-G\left(p_{t}^{M}\right)\right)$ is decreasing in $t$, for any $t^{\prime}>t$ we have $-\left(1-G\left(p_{t^{\prime}}^{M}\right)\right)>-\left(1-G(r)^{2}\right)$ so that for no such $t^{\prime}$ will the equality hold. Therefore the solution is unique. For existence note that at $t=r$ the LHS is zero, whereas the RHS is strictly positive. For $t$ sufficiently low, the LHS will exceed the RHS. To prove this, find $x$ such that $(1-G(x))>\left(1-G(r)^{2}\right)$, then we can find $t$ sufficiently low so that $(1-G(x))(x-t)>\left(1-G(r)^{2}\right)(r-t)$, then for this $t$ by the definition of $p_{t}^{M}$ we have $\left(1-G\left(p_{t}^{M}\right)\right)\left(p_{t}^{M}-t\right) \geq(1-G(x))(x-t)>\left(1-G(r)^{2}\right)(r-t)$. Therefore the solution has to exist. 
For $\underline{t}<\bar{t}$, note that by the definition of $\underline{t}$, at $t=\underline{t}$ the LHS of $\left(1-G(r)^{2}\right)(r-t)=$ $\left(1-G\left(p_{t}^{M}\right)\right)\left(p_{t}^{M}-t\right)$ has to exceed the RHS. We cannot have $\underline{t}>\bar{t}$ because for any $t>\bar{t}$ the RHS has to exceed the LHS (see the argument above), which then contradicts the statement that at $\underline{t}$ the opposite is true, therefore $\underline{t}<\bar{t}$.

Assume $t<\underline{t}$, then $p_{t}^{I M}<r$ by the definition of $p_{t}^{I M}$ and $\underline{t}$. First let us prove that $w^{*}=p_{t}^{I M}-t-\frac{1-G\left(p_{t}^{I M}\right)^{2}}{2 \int_{p_{t}^{I M}}^{r} g(v)^{2} d v+2 g\left(p_{t}^{I M}\right) G\left(p_{t}^{I M}\right)+\alpha(1-G(r)) g(r)}$ with $p\left(w^{*}\right)=p^{*}=p_{t}^{I M}$ is indeed an equilibrium. For downstream firms pricing was characterized earlier, and indeed for $c=$ $p_{t}^{I M}-\frac{1-G\left(p_{t}^{I M}\right)^{2}}{2 \int_{p_{t}^{I M}}^{r} g(v)^{2} d v+2 g\left(p_{t}^{I M}\right) G\left(p_{t}^{I M}\right)+\alpha(1-G(r)) g(r)}$ they will set $p\left(w^{*}\right)=p_{t}^{I M}$. The upstream supplier has no profitable deviation because the vertical structure achieves maximum possible profits with $p\left(w^{*}\right)=p_{t}^{I M}$. To show that no other equilibria exists, assume that consumers expect $p^{*} \neq p_{t}^{I M}$. There are two cases. First consider $p^{*}<p_{t}^{I M}$. For this to be equilibrium, the upstream supplier has to charge $w^{*}=p^{*}-t-\frac{1-G\left(p^{*}\right)^{2}}{2 \int_{p^{*}}^{r} g(v)^{2} d v+2 g\left(p^{*}\right) G\left(p^{*}\right)+\alpha(1-G(r)) g(r)}$, but then a upward deviation in $w$ (with a corresponding increase in $F$ ) would increase $p^{*}$ and would thus increase the upstream supplier's profits. For $p^{*}>p_{t}^{I M}$ there are further two cases, with $p^{*} \leq r$ and $p^{*}>r$. In the first case the upstream supplier can marginally reduce $w$ and increase total and thus its own profits. In the second case, consumers would not search if prices were equal to $p^{*}$, but then each downstream firm would charge $p_{c}^{M}$, therefore it would be optimal for the upstream supplier to set $w^{*}=0$, which then means that $p^{*}=p_{t}^{M}$, which by $t<\underline{t}$ then contradicts $p^{*}>r$ because $r$ is the integrated monopoly price for $\underline{t}$, so $p_{t}^{M}$ has to be lower both because it is a single-product monopoly price and for a lower marginal cost $t$.

Now consider $t \in[\underline{t}, \bar{t}]$. Here we have to prove that $w^{*} \in\left[c_{1}-t, c_{2}-t\right]$ is an equilibrium. There may be another equilibrium where consumers do not search, $w^{*}=0$ and $p\left(w^{*}\right)=p_{t}^{M}$ for $\alpha>0$, but we ignore them here as explained above. Given that $t \in[\underline{t}, \bar{t}], p^{*}=r$ and downstream pricing behavior, the upstream supplier cannot do better by lowering $w$ (there is no change in $p(w)$ or there is a reduction, which then reduces total profits). An increase in $w$ may again have no effect, or lead to an increase of $p(w)$ which the triggers an increase in $p^{e}$ above $r$ and thus no consumer searches. The best possible profit of the vertical structure in that case is $2\left(1-G\left(p_{t}^{M}\right)\right)\left(p_{t}^{M}-t\right)$, which by $t<\bar{t}$ is lower than $2\left(1-G(r)^{2}\right)(r-t)$, the latter being the equilibrium profit of the upstream firm, so no deviation is profitable. As for downstream firms, their pricing for $p^{*}=r$ given in Proposition 2 induces them to charge $p(w)=\bar{p}=r$ for all $w^{*} \in\left[c_{1}-t, c_{2}-t\right]$.

Finally, when $t>\bar{t}$, if the upstream supplier charges $w^{*}=0$ and $p^{*}=p_{t}^{M}$ consumers would not search because $p_{t}^{M}>r$ by the definition of $\bar{t}$ as the solution to $\left(1-G(r)^{2}\right)(r-t)=$ $\left(1-G\left(p_{t}^{M}\right)\right)\left(p_{t}^{M}-t\right)$ which implies that form $t=\bar{t}$ we should have $r<p_{t}^{M}$, and so for $t>\bar{t}$ this inequality is preserved. Conditional on consumers not searching, and $w^{*}=0$, the downstream firms will indeed optimally charge $p\left(w^{*}\right)=p_{t}^{M}$. The upstream firm cannot deviate profitably. A deviation to $w>0$ is unprofitable because it will increase already optimal downstream price. A deviation to $w<0$ may at best lead to consumers 
searching, which given that $p_{t}^{I M}>r$ can at most generate $2\left(1-G(r)^{2}\right)(r-t)$ for the vertical structure, which by the definition of $\bar{t}$ is lower than $2\left(1-G\left(p_{t}^{M}\right)\right)\left(p_{t}^{M}-t\right)$. No other equilibrium may exist. For $p^{*}>r$ and $p^{*} \neq p_{t}^{M}$, consumers would not search, and then the upstream firm would induce $p(w)=p_{t}^{M}$. For $p^{*}<r$, conditional on consumers searching, the upstream firm would want to increase $p(w)$ to move it closer to $p^{I M}$, which is a profitable deviation.

Corollary 5. For any $\alpha<1$ there exist threshold values of $s$, denoted by $\underline{s}$ and $\bar{s}$, with $\underline{s}<\bar{s}$, such that (i) if $s<\underline{s}$, the upstream manufacturer has a unique optimal wholesale price $w^{*}$ that is such that the downstream price is $p^{*}=p_{t}^{I M}$, (ii) if $s \in[\underline{s}, \bar{s}]$, any $w^{*} \in\left[c_{1}-t, c_{2}-t\right]$ is optimal for the upstream manufacturer resulting in an equilibrium downstream price of $r$, and (iii) if $s>\bar{s}$, the optimal upstream price is $w^{*}=0$ resulting in an equilibrium downstream price of $p_{t}^{M}$.

Proof. First let us show that $\underline{s}<\bar{s}$. Both exist by $p_{t}^{I M} \in[\underline{v}, \bar{v}]$ and the definition of $r$. The inequality follows from $p_{t}^{I M}>p_{t}^{M}$ and $\left(1-G(x)^{2}\right)(x-t)>(1-G(x))(x-t)$.

The rest of the proof follows the same lines as the proof of Proposition 4. For this note that $s<\underline{s}$ iff $t<\underline{t}$, and $s<\bar{s}$ iff $t<\bar{t}$.

Proposition 6. For $\alpha=1$ there exist threshold values of $t$, denoted by $\underline{t}$ and $\bar{t}^{\prime}$ with $\underline{t}<\bar{t}^{\prime}$, such that (i) if $t<\underline{t}$ the upstream manufacturer has a unique optimal wholesale price $w^{*}$ that is such that the downstream price is $p^{*}=p_{t}^{I M}$, (ii) if $t \in\left[\underline{t}, \bar{t}^{\prime}\right.$ ), no pure strategy equilibrium exists, and (iii) if $t \geq \bar{t}^{\prime}$, the optimal upstream price is $w^{*}=0$ resulting in an equilibrium downstream price of $p^{*}=p_{t}^{M}$.

Proof. We first show $\bar{t}^{\prime}>\underline{t}$. This follows from respective definitions and the fact that $\frac{1-G(r)^{2}}{2 G(r) g(r)}-\frac{1-G(r)}{g(r)}=\frac{(1-G(r))^{2}}{2 G(r) g(r)}>0$. For $t \leq \underline{t}$, the proof is very similar to the proof for $\alpha<1$. Namely, the upstream supplier can charge such $w$ that downstream firms charge $p(w)=p_{t}^{I M}$, which then achieves maximal profits for the supplier and thus it has no profitable deviation. For $w^{*}=p_{t}^{I M}-t-\frac{1-G\left(p_{t}^{I M}\right)^{2}}{2 \int_{p_{t}^{I M}}^{r} g(v)^{2} d v+2 g\left(p_{t}^{I M}\right) G\left(p_{t}^{I M}\right)+(1-G(r)) g(r)}$, as shown in the previous section, downstream equilibrium will result in $p_{t}^{I M}$ charged downstream, and because $t \leq \underline{t}, p_{t}^{I M} \leq r$, so consumers will search, thus we have an equilibrium. For $t>\bar{t}^{\prime}$, it is easy to see that $w^{*}=0$ is optimal for the upstream firm. In this case the only equilibrium downstream is such that $p\left(w^{*}\right)=p_{t}^{M}$, and consumers do not search because by the definition of $\bar{t}^{\prime}$ we have $p_{t}^{M}>r$. Since beliefs do not change with prices, there can be no equilibrium where consumers set $p^{*}<r$ because then they would search, and so the upstream supplier would induce $p(w)=p_{t}^{I M}>r$ which then would contradict $p^{*}<r$. Given that consumers will not search in equilibrium, the upstream firm cannot do better than $w^{*}=0$ and extract all downstream profits with $F$. Finally, for $t \in\left(\underline{t}, \bar{t}^{\prime}\right]$ we need to prove that no pure strategy equilibrium exists. Assume to the contrary that there is $w^{*}$ 
that leads to such an equilibrium. Consumer beliefs have to be correct, so equilibrium $p^{*}=p\left(w^{*}\right)$. If $p^{*} \leq r$, then consumers who draw low utilities will search in equilibrium, and this will not depend on actual prices because $\alpha=1$. This then means that the upstream firm would want to set such $w$ that $p(w)=p_{t}^{I^{\prime} m}>r$ (which follows from $t>\underline{t}$ ), thus leading to a contradiction. For $p^{*}>r$, consumers will not search, so the downstream equilibrium price will $p_{c}^{M}$, which then means that $w^{*}=0$ so the upstream firm maximizes total profits subject to no search, which is achieved by $p_{t}^{M}$. However, because $t<\bar{t}^{\prime}$, $p_{t}^{M}<r$, so since we consumers have to set $p^{*}=p_{t}^{M}$, we get a contradiction.

Proposition 7. Cost pass-through $\rho(t)$ is given by

$$
\rho(t)= \begin{cases}\frac{1}{2+\left(p_{t}^{I M}-t\right)\left(\frac{\left.g^{\prime I M}\right)}{g\left(p^{I M}\right)}+\frac{g\left(p^{I M}\right)}{G\left(p^{I M}\right)}\right)} & \text { if } t<\underline{t} \\ 0 & \text { if } \underline{t} \leq t \leq \bar{t} \\ \frac{1}{2+\left(p_{t}^{M}-t\right)\left(\frac{\left.g^{\prime M}\right)}{g\left(p^{M}\right)}\right)} & \text { if } t>\bar{t},\end{cases}
$$

Proof. The pass through can be obtained through implicit differentiation using the definitions of $p_{t}^{I M}$ and $p_{t}^{M}$. The ranges are given by Proposition 4 . 